\title{
Satellite-derived estimation of environmental suitability for malaria vector development in Portugal
}

\author{
A. Benali a,e,*, J.P. Nunes ${ }^{\text {a,c }}$, F.B. Freitas ${ }^{\text {b }}$, C.A. Sousa ${ }^{\text {b }}$, M.T. Novo ${ }^{\text {b }}$, P.M. Lourenço ${ }^{a}$, J.C. Lima ${ }^{\text {a,d }}$, \\ J. Seixas ${ }^{\text {a }}$, A.P.G. Almeida ${ }^{\text {b }}$ \\ a CENSE - Centre for Environmental and Sustainability Research, Departamento de Ciências e Engenharia do Ambiente, Faculdade de Ciências e Tecnologia, Universidade Nova de Lisboa, \\ 2829-516 Caparica, Portugal \\ ${ }^{\mathrm{b}}$ UPMM (U074 FCT), Instituto de Higiene e Medicina Tropical, Universidade Nova de Lisboa, R. Junqueira 100, 1349-008 Lisboa, Portugal \\ c CESAM \& Dept. Environment and Planning, University of Aveiro, Portugal \\ ' ICAAM - Instituto de Ciências Agrárias e Ambientais Mediterrânicas, Universidade de Évora - Núcleo da Mitra, Apartado 94, 7002-254 Évora, Portugal \\ e CEF - Centro de Estudos Florestais, Instituto Superior Agronomia, Universidade de Lisboa, Tapada da Ajuda 1349-017, Lisboa, Portugal
}

\section{A R T I C L E I N F O}

\section{Article history:}

Received 25 July 2013

Received in revised form 17 January 2014

Accepted 18 January 2014

Available online 26 February 2014

\section{Keywords:}

An. atroparvus

Temperature

Habitat suitability

Remote sensing

MODIS

Portugal

Malaria

Vector-borne diseases

\begin{abstract}
A B S T R A C T
Malaria was endemic in Europe for more than two millennia until its eradication in the 1970s. Recent autochthonous cases registered in Greece have increased the awareness regarding the threat of malaria re-emergence in Southern Europe. Currently, the presence of competent vectors, suitable environmental conditions and the evidences of a changing climate may increase the widespread re-emergence of malaria in Southern Europe. This work focused on determining the current relationships between environmental factors and the density of the former malaria vector Anopheles atroparvus in Portugal, a previously endemic country. Adult females were sampled and vector density was estimated in 22 sites in Southern Portugal between 2001 and 2010 and related with land cover and satellite-derived air temperature and vegetation indices. The relationship between vector density and local larval habitat, temperature and, in a broader sense, to environmental suitability, was assessed using a statistical modelling approach.

Results showed that present environmental conditions are suitable for vector development at high densities and the spatial and temporal patterns closely resemble the ones registered in the past endemic period. The use of satellite-derived data, together with statistical models, allowed the extrapolation of suitable environmental conditions for vector development from site-level to the Portuguese mainland territory. This work also improved the baseline knowledge needed to understand the potential impacts of future environmental changes on vector density and, indirectly, on the risk of malaria re-emergence.
\end{abstract}

(C) 2014 Elsevier Inc. All rights reserved.

\section{Introduction}

Human malaria is an infectious disease caused by Plasmodium parasites and transmitted by mosquitoes of the genus Anopheles. It is an important public health problem with more than 200 million cases reported per year, of which 1 million result in death (WHO, 2010). Malaria was endemic in Europe for more than two millennia (Kuhn, Campbell-Lendrum, \& Davies, 2002), but socio-economic and agricultural changes (Reiter, 2000), and the implementation of control campaigns led to its eradication in the 1970s (WHO, 1978). Since then, imported (Baldari et al., 1998; Castro, Cardoso, Queirós, \& Gonçalves, 2004) and autochthonous cases (Danis et al., 2011; Vakali et al., 2012) have been reported in European malaria-free countries.

\footnotetext{
* Corresponding author at: Centro de Estudos Florestais, Instituto Superior Agronomia, Universidade Técnica Lisboa, Tapada da Ajuda 1349-017, Lisboa, Portugal. Tel.: + 351 964291869; fax: + 351213653338.

E-mail address: aklibenali@gmail.com (A. Benali).
}

The present status of anophelism (i.e. the presence of Anopheles mosquitoes) without malaria in most of Europe indicates that current socio-economic conditions, particularly due to the changes that have reduced the human exposure to mosquitoes and the rapid treatment of imported cases, as well as environmental conditions, maintain the basic case reproduction number $\left(\mathrm{R}_{\mathrm{o}}\right)$ below 1 (e.g. Kuhn et al., 2002). However, the existence of i) competent vectors, ii) suitable climate, iii) proximity and historical connection to Africa and Asia, iv) pronounced environmental changes and $\mathrm{v}$ ) high immigration rates, may potentially re-introduce malaria especially in southern Europe (Sainz-Elipe et al., 2010). In particular, predicted future climatic conditions may be potential drivers of vector-borne disease re-emergence in temperate regions (IPCC, 2007; Lindsay, Hole, Hutchinson, Richards, \& Willis, 2010; Martens et al., 1999). Global warming can significantly increase mosquitoes' vectorial capacity for several reasons, including the reduction of the Plasmodium extrinsic incubation period, the extension of the favourable mosquito breeding period, and the increase in adult vector density, longevity and biting rate (Jetten, Martens, \& Takken, 1996; Calheiros, Santos, Calheiros, \& Kovats, 2006; Lafferty, 2009). Some authors have 
stated that the current potential disease transmission window is significant and can widen with temperature increase, as well as expand to other presently non-suitable areas (Lindsay et al., 2010; Sainz-Elipe et al., 2010; Shroeder \& Schmidt, 2008). Others have shown that the historical malaria distribution in Europe was more strongly related to other factors than climate (Kuhn, Campbell-Lendrum, \& Davies, 2004). The recent autochthonous cases registered in Greece (Danis et al., 2011; Vakali et al., 2012) have increased the awareness regarding the threat of potential malaria re-emergence in southern Europe.

In the absence of disease transmission, the risk of malaria reemergence can be assessed using vector density as a rough indicator (Kuhn et al., 2002). Although the approach is simple, the results must be addressed with caution because several other factors interplay and contribute to the risk of re-emergence. Anopheles atroparvus is presently widespread through most of Europe (Kuhn et al., 2002; Sinka et al., 2010) and is considered an efficient malaria vector in western Europe (Capinha et al., 2009; Sainz-Elipe et al., 2010). Since vectors' development, behaviour, distribution and vectorial capacity are highly dependent on environmental factors (Mellor \& Leake, 2000), these relationships must be understood in order to assess the impact of future changes in mosquitoes' abundance and distribution (Kuhn et al., 2002; Rogers, Randolph, Snow, \& Hay, 2002). On the other hand, the completion of the extrinsic incubation period of the parasite within the mosquito vector is also dependent on temperature, and therefore may also be affected by environmental factors (Warrell \& Gilles, 2002).

The interactions between environmental conditions and disease vectors have been studied worldwide (e.g. Hay, Snow, \& Rogers, 1998; Lindsay, Parson, \& Thomas, 1998). However, for Europe, there is still limited knowledge of how environmental factors interplay and influence the dynamics of local malaria vectors. A small number of studies have focused on some aspects of the relationships between anopheline species, particularly for An. atroparvus, and environmental factors. Improved knowledge of these relationships is crucial to understand the dynamics of anopheline species (Cailly et al., 2011; Romi et al., 2012; Tran et al., 2008). Some conclusions found in the literature include:

- An. atroparvus is preferentially zoophilic and rests in animal sheds and stables (Bates \& Hackett, 1938; Cambournac \& Hill, 1938; Hutchinson, 2004; Pires, Ribeiro, Capela, \& da Cunha Ramos, 1982).

- An. atroparvus requires water for breeding and vegetation for resting and predator protection (Cambournac \& Hill, 1938; Hutchinson, 2004; WHO, 1982). Thus, land cover and land use play an important role in the mosquitoes' development (Dale \& Knight, 2008; Minakawa et al., 2005; Pope et al., 1994; Shililu et al., 2003). The immature stages of An. atroparvus are usually found in clean, sunlit, standing fresh or brackish water (Bates \& Hackett, 1938; Cambournac \& Hill, 1938; WHO, 1982).

- Some mosquitoes depend directly on rainfall for the formation of breeding sites. Others use stable and permanent habitats where the lack of rain may not be a relevant factor for mosquito larval production (Service \& Townson, 2002). Artificial irrigation and open water bodies provide important rainfall-independent breeding sites where An. atroparvus is often found (e.g. Sainz-Elipe et al., 2010).

- Temperature influences mosquito survival, behaviour and larval-topupal development time (Cambournac \& Hill, 1938). Although known to be a very tolerant species, the survival and development of $A n$. atroparvus is constrained in locations with high diurnal temperature ranges (Kuhn et al., 2002). Furthermore, very low temperature can cause high mortality in resting females, especially if temperatures drop below $0{ }^{\circ} \mathrm{C}$ (Hutchinson, 2004), and high temperature can reduce adult survival, especially above $40{ }^{\circ} \mathrm{C}$ (Cambournac \& Hill, 1938).

The success and usefulness of studying the relationships between environmental drivers and mosquito distribution depend on the selection of suitable variables at the appropriate spatial and temporal scales (Pope et al., 1994). Moreover, predictions over unsurveyed areas can only be established using environmental parameters acquired at a suitable spatial and temporal resolution over a wide geographic range (Kuhn et al., 2002; Rogers et al., 2002). Satellite data is suitable to provide environmental surrogates and has been used to study vector-borne diseases at a large spatial scale (e.g. Green \& Hay, 2002; Machault et al., 2011; Rogers et al., 2002). Several studies have used medium-high resolution satellite data (e.g. Landsat, Mikonos, SPOT) to identify and characterize potential mosquito larval habitats (Hay et al., 1998; Mushinzimana et al., 2006; Pope et al., 1994). The spatial and temporal variability of satellite-derived vegetation indices has been correlated with the dynamics of vector populations (Britch et al., 2008; Lourenço et al., 2011; SainzElipe et al., 2010). Coarse satellite-derived meteorological surrogates have also been related to the dynamics of vector populations (Hay, Tucker, Rogers, \& Packer, 1996, 1997; Rogers, Hay, \& Packer, 1996).

Improvement of the current knowledge on the potential reemergence of malaria in Europe requires further in-depth analysis regarding the environmental drivers of one of the most widespread European vector species (An. atroparvus), aiming to enhance our ability to estimate potential changes in its distribution and, indirectly, changes in the risk of re-emergence. Few studies have integrated the multiple environmental components that influence European vectors, at the appropriate spatial-temporal scale. Some of these multi-factorial studies used coarse climatic and land cover data (e.g. Kuhn et al., 2002), not capturing important fine-scale environmental features, such as climatic variability, and land cover fragmentation and heterogeneity. Furthermore, the use of vector presence/absence data has been more commonly used than adult vector abundance, despite the high importance of the latter for epidemiological studies, especially for the $\mathrm{R}_{0}$ calculation, and close connection with previous malaria transmission periods (e.g. Capinha et al., 2009; Rogers et al., 2002). The few studies that have used adult vector abundance in Europe focused on very small areas (e.g. Lourenço et al., 2011; Sainz-Elipe et al., 2010; Tran et al., 2008), lacking of a regional scope which is crucial for understanding the dynamics of vector density at different scales. Therefore, if adult vector abundance could be estimated at a regional level, indicating habitat suitability and favourable environmental conditions. Moreover, in areas where diseases are vector-density dependent, as it was the case of malaria in Portugal, the estimation of adult vector abundance can help define more accurately regions prone to outbreaks. This would certainly constitute a considerable advantage over just presence/absence data.

The purpose of this work is to overcome some of these limitations, by integrating satellite-derived environmental drivers, such as air temperature, land cover and vegetation indices at the appropriate spatio-temporal scale in order to identify suitable conditions for the development of An. atroparvus in Portugal. We aim at improving the state-of-knowledge on vector density, one of the multiple factors responsible for malaria transmission.

\section{Methodology and data}

\subsection{Study areas}

The study was performed in Portugal, located in south-western Europe. The Northwest of the country has a humid Mediterranean climate, with cold winters and mild summers; the vegetation is mostly forest, although there are large irrigated areas (rice and corn) and marshlands close to the estuaries of major rivers, where malaria was endemic in the past. The Northeast has a sub-humid Mediterranean climate with higher temperature amplitudes, covered mostly by forests and shrublands; temperature can reach high values in summer, especially in the plateaus surrounding the upper valley of the Douro River, which was also an endemic malaria region. The South has a dry Mediterranean climate, with mild winters and warm summers, especially in the interior. The land cover includes agroforestry and large areas of irrigated crops (rice and corn) and marshland, especially near the coastline. 
Malaria was endemic in Portugal until 1973 and was eradicated through the use of vector control measures and patient treatment (Bruce-Chwatt \& Zulueta, 1977). Nevertheless, some imported infection cases have been registered since then (Castro et al., 2004). During the endemic period, the transmission of malaria was mosquito-density dependent and occurred for about 4-5 months, between the end of April and mid-October, while vector density peaked between June and August depending on the region (Cambournac, 1942). During this period, An. atroparvus was the only mosquito species responsible for malaria transmission in Portugal and nowadays it is still the most abundant anopheline, widespread throughout the entire country (Almeida et al., 2008; Ribeiro, Pires, \& Capela, 1988). The current spatial distribution of this species' habitat suitability presents similarities with former malarial areas (Capinha et al., 2009).

The study area was divided in four distinct study regions in southern Portugal, as shown in Fig. 1, and the extrapolation was made for the entire territory.

Comporta is located in a flat coastal area with a very heterogeneous landscape dominated by wetlands, irrigated agriculture and natural vegetation. Due to its proximity to the Atlantic Ocean, temperature is mild with low daily amplitudes and average temperature is between 10 and $26{ }^{\circ} \mathrm{C}$, respectively for winter and summer. The presence of irrigated agriculture, mainly rice fields, leads to high vegetation productivity and the presence of standing water during spring and summer, when temperature is highest. Until the 1950s this region was a hyper endemic area of malaria (Cambournac, 1942, 1994).

The Alqueva region is semi-arid with high diurnal temperature amplitudes and average temperature between 5 and $30{ }^{\circ} \mathrm{C}$, in winter and summer, respectively. The hot and dry climate supports a land cover dominated by non-irrigated agriculture and natural vegetation surrounding the Guadiana valley. In 2002, the Alqueva dam, the largest freshwater artificial reservoir in Europe, was built to provide water for irrigation purposes and has gradually changed agricultural cultures and practices. Additionally, it has impacts on the surrounding environmental conditions that affect mosquito development and survival, such as air temperature, relative humidity and breeding habitats. Malaria was present in some areas of Alqueva, as well as in other parts of the Guadiana basin at endemicity levels ranging from low to moderate (Cambournac, 1942).

The two remaining study regions are located in Algarve, at the southern coast of Portugal. Algarve has a strong East to West spatial gradient of average and diurnal temperature range, justifying two separate study areas: one with a warmer and a more arid climate in the East, and another with milder temperature in the Center-West. The annual average temperature ranges in the East (which comprises the downstream region of the Guadiana valley) are similar to those in Alqueva, and in the Center/West are similar to Comporta, due to the Atlantic Ocean influence. The land cover is mainly composed by natural vegetation, varied agricultural covers (irrigated and non-irrigated) and wetlands. Since Algarve is a highly touristic region a significant number of irrigated leisure facilities, such as golf fields, are also present. In the past, Algarve presented a single, low-endemic, malarial region located in the Centre (Cambournac, 1942). Recently, this particular region became part of surveillance studies (Freitas, Novo, Esteves, \& de Almeida, 2012) due to the report of cases of mosquito-borne disease infections (Connell et al., 2004).

\subsection{Field data}

Previous work in Portugal showed that An. atroparvus is best sampled by hand mechanical aspiration while resting indoors in animal shelters, as it rarely appears in CDC light traps (Almeida et al., 2008; Sousa, 2008). The collecting method was optimized by aspirating mosquitoes resting in animal shelters for $10 \mathrm{~min}$, during which experienced collectors were able to catch a representative sample of mosquitoes, when high densities were present. That time period is sufficient to survey the whole shelter before declaring it devoid of mosquitoes in low density population conditions. The highest possible number of samples was collected in each locality, within time and funding limitations, capturing their variability at type of shelter and animal host present (Lourenço et al., 2011). Collections were made in low height animal shelters, where hosts were present all over the year and morphologically identified using Ribeiro and Ramos (1999) identification keys. According to previous morphological and molecular studies (Ribeiro et al., 1988; Sousa, 2008), An. atroparvus is the only species of the Maculipennis complex present in the study area.

A total of 521 mosquito samples were used for this work, collected in a total of 22 sites distributed throughout the four study areas (Fig. 1), between 2001 and 2010 (Table 1; see Supplement). The time span, sampling frequency and the number of sites varied between regions since they were collected during several entomological surveys. Since only the females are responsible for the transmission of malaria, vector density (hereafter VD) was calculated as the average number of An. atroparvus females captured per collector per minute (fem. col. ${ }^{-1} \mathrm{~min}^{-1}$ ).

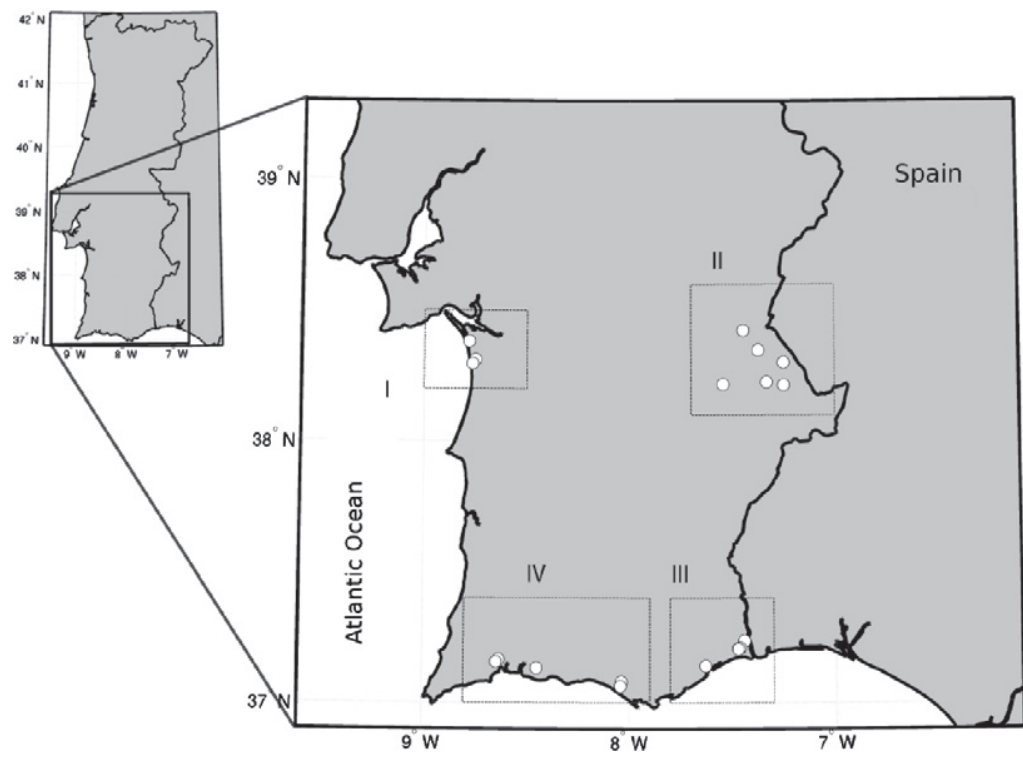

\author{
I Comporta \\ II Alqueva \\ III East Algarve \\ IV Center/West Algarve
}

Fig. 1. Sampling areas' distribution in Southern Portugal. The different sampling regions are delimited in black squares and the white circles are the sampling sites. 
Table 1

Mosquito sampling global data characteristics.

\begin{tabular}{|c|c|c|c|c|}
\hline Region & Temporal coverage & Sampling frequency & Number of sites & Number of samples \\
\hline Comporta & 2001-2005 & Bi-weekly & 3 & 209 \\
\hline Alqueva & 2004-2005, 2007 & Monthly & 6 & 169 \\
\hline East Algarve & 2009-2010 & Monthly & 5 & 70 \\
\hline Centre/West Algarve & $2009-2010$ & Monthly & 8 & 73 \\
\hline Total & 2001-2005, 2007, 2009-2010 & Bi-weekly and monthly & 22 & 521 \\
\hline
\end{tabular}

\subsection{Satellite data}

Satellite-derived air minimum, maximum and average temperature (T2m, or temperature at $2 \mathrm{~m}$ height above ground surface) datasets for 2001-2010, derived from MODIS Land Surface Temperature and auxiliary data (Benali, Carvalho, Nunes, Carvalhais, \& Santos, 2012) were used in this study. These datasets with $1 \mathrm{~km}-8$ day spatial and temporal resolution have a high reported accuracy providing reliable information of $\mathrm{T} 2 \mathrm{~m}$ distribution across the entire study region and period.

The Corine Land Cover 2006 (CLC2006; EEA, 2007), derived from satellite data, was used for the static characterization of land cover, while the MODIS Collection 5 (C5) 16 day NDVI (Normalized Difference Vegetation Index) and EVI (Enhanced Vegetation Index) datasets provided dynamic characterization of vegetation development stage and greenness integrating the effects of several environmental factors (Britch et al., 2008). Both products were linearly interpolated to 8 day periods to match the temporal resolution of the T2m dataset. The Normalized Difference Water Index (NDWI; Gao, 1996) was produced using MODIS $500 \mathrm{~m}$ weekly surface reflectance to characterize the vegetation water content and presence of surface water.

To account for mosquito dispersal from larval habitats to sampling sites, environmental data was related with site-level VD samples by spatially aggregating the former using circular buffers. There is little information regarding the flight range of An. atroparvus, thus we chose a wide range of radii between $500 \mathrm{~m}$ and $5 \mathrm{~km}$ following previous works' (Cambournac \& Hill, 1938; Kaufmann \& Briegel, 2004; Tran et al., 2008). For each buffer, a set of spatial statistics was calculated: i) average; ii) percentile 75 ; iii) percentile 90 ; and, iv) maximum. The spatial integration of data in several radii helps to account for the variability of mosquitoes' flight range and habitat heterogeneity, and their impact on samplings done at a much smaller spatial scale (Lourenço et al., 2011; Tran et al., 2008).

Significant time lags in the response of VD to changes in environmental conditions can occur mainly due to the variability in the eggto-adult development times (Cambournac \& Hill, 1938; WHO, 1982). To account for this process, the relations between VD and environmental (climatic and vegetation) variables were analysed considering also data acquired one to five weeks prior to the sampling dates.

\subsection{Relations between vector density and environmental drivers}

\subsubsection{Site-level relationships}

The presence of productive larval sites has a close relationship with the distribution of adult mosquitoes (Cailly et al., 2011; Machault et al., 2011; Romi et al., 2012; Tran et al., 2008). The relationship between VD and the mosquito larval habitat and temperature suitability were studied at a site-level scale. It was assumed that a given area can support vector density up to a certain carrying capacity due to its habitat conditions (Lourenço et al., 2011) and this ceiling value was reflected by the maximum VD over time. It was also assumed that the maximum VD estimated in each site occurred at optimum climate conditions, thus, its inter-site variability was mainly related with variations of the surrounding mosquito larval habitat suitability.

Relationships between landscape surrogates and maximum VD were analysed using two approaches: static suitability, assessed through
CLC2006 land-cover, and dynamic suitability (in time), assessed through MODIS vegetation indices. In the first approach, a suitability score between 0 and 1 was assigned to each CLC2006 land cover class (Table 2) based on both generic Anopheline and specific An. atroparvus literature (Adamovic, 1975; Bates \& Hackett, 1938; Cambournac, 1994; Cambournac \& Hill, 1938; Hackett \& Missiroli, 1935; Mushinzimana et al., 2006; Pires et al., 1982; Shililu et al., 2003; Takken, Geene, Adam, Jetten, \& van der Velden, 2002; Tran et al., 2008; WHO, 1982). Some authors have previously used this suitability ranking approach based on land cover classes (Capinha et al., 2009; Dambach et al., 2009; Pope et al., 1994). Rice fields, other irrigated agriculture, sports and leisure facilities were all defined as optimum breeding habitats. The distance to these optimum breeding sites was also used as a static surrogate variable (Mushinzimana et al., 2006; Tran et al., 2008). In the second approach, both MODIS vegetation indices and land cover variables were combined to take into account the seasonal landscape dynamics.

Land cover suitability, vegetation indices and distance to optimum breeding sites were spatially integrated using buffers as previously described in Section 2.3. For the latter variable, spatial statistics (minimum, percentiles 10 and 25, and average) were calculated to reflect higher suitability due to habitat proximity. Two numerical approaches were used to understand how selected environmental variables could explain maximum VD: i) simple linear relations, following Lourenço

Table 2

Land cover larval suitability rank

\begin{tabular}{ll}
\hline Land cover class name & Larval habitat score \\
\hline Rice fields & 1 \\
Permanently irrigated land & 1 \\
Sport and leisure facilities & 1 \\
Water bodies & 0.75 \\
Continuous urban fabric & 0.5 \\
Discontinuous urban fabric & 0.5 \\
Non-irrigated arable land & 0.5 \\
Salt marshes & 0.5 \\
Industrial or commercial units & 0.25 \\
Mineral extraction sites & 0.25 \\
Construction sites & 0.25 \\
Vineyards & 0.25 \\
Fruit trees and berry plantations & 0.25 \\
Pastures & 0.25 \\
Land principally occupied by agriculture, & 0.25 \\
with significant areas of natural vegetation & \\
Water courses & 0.25 \\
Coastal lagoons & 0.25 \\
Estuaries & 0.25 \\
Olive groves & 0.1 \\
Annual crops associated with permanent crops & 0.1 \\
Complex cultivation patterns & 0.1 \\
Agro-forestry areas & 0.1 \\
Broad-leaved forest & 0.1 \\
Coniferous forest & 0.1 \\
Mixed forest & 0.1 \\
Natural grasslands & 0.1 \\
Moors and heath land & 0.1 \\
Sclerophyllous vegetation & 0.1 \\
Transitional woodland-shrub & 0.1 \\
Beaches, dunes, sands & 0 \\
Salines & 0 \\
Sea and ocean & 0 \\
\hline & \\
\hline
\end{tabular}


et al. (2011), and ii) non-linear multi-variable models (e.g. exponential, logistic), using two independent variables at each time and testing five different general equation types. We used an exploratory statistical approach without assuming any pre-established type of relationships and/or importance of each variable.

Temperature suitability for mosquito development and survival was studied by applying the five different models. Some authors have stated that vector development and survival may be reduced not only at low but also at high temperature (e.g. Hutchinson, 2004; Kuhn et al., 2002; Logan, Wolesensky, \& Joern, 2006), thus this unimodal response should be accounted in vector modelling (Lafferty, 2009; Rogers, 2006). The Remote Vector Model developed by Lourenço et al. (2011) was applied, however since it is based on a logistic equation it does not account for upper temperature limitations. Alternatively, four other models were also assessed: Gaussian, log-logistic, first to third degree polynomials and an inverse second degree polynomial equation (Macedo, Ferreira, \& Duarte, 1998; here after PI curve). The models were calibrated for all samples and for each region individually. To describe the temperature effect of a given $\mathrm{T} 2 \mathrm{~m}$ value, all the equations' outputs were normalized considering their maximum calculated value to represent a limiting factor, i.e. varying from 0 to 1 . An optimum temperature effect threshold (hereafter, $\mathrm{T}_{\mathrm{opt}}$ ) of 0.7 was defined empirically by comparing the distribution of calculated temperature effect and VD (see 3.4.1). All T2m values above $T_{\text {opt }}$ were considered optimum and suitable for vector development. $\mathrm{T}_{\text {opt }}$ comprises an important ecological concept because it reflects the average $\mathrm{T} 2 \mathrm{~m}$ around which vector development and survival are not significantly limited by temperature fluctuations.

To adjust the relations between VD and both temperature and larval habitat suitability, a simple optimization scheme was implemented with the aim of minimizing the square of absolute errors by adjusting the model parameters accordingly (e.g. Benali et al., 2012). Two statistical measures were used to evaluate model adjustment: the Nash-Sutcliffe model efficiency (MEF) index, a measure of model predictive power (Nash \& Sutcliffe, 1970), and the Pearson coefficient $\left(\mathrm{r}^{2}\right)$, used as a measure of correlation and proportion of observed variability accounted by the model (Steel \& Torrie, 1960).

Finally, the relations between the spatial-temporal variability of VD and the dynamics of both larval habitat and temperature suitability were analysed together aiming to identify relevant environmental patterns. We considered different subsets to identify the presence of different clustered relations due to regional, host type and mosquito larval habitat suitability differences. Three classes were considered for the latter: low and high suitability, referring to sites where maximum VD was below and above the percentiles 25 and 75, respectively, and the medium suitability referring to the remaining sites.

\subsubsection{Spatial mapping}

Based on the site-level relationships between VD and environmental drivers, the suitability for An. atroparvus development was mapped for the entire Portuguese mainland territory. The technique was based on two approaches: i) solely temperature, and ii) temperature and larval habitat suitability.

In the first approach, the T2m-based model with the best statistical adjustment was adopted to describe the temperature suitability for vector development. The satellite-derived $\mathrm{T} 2 \mathrm{~m}$ data set was used to generate $1 \mathrm{~km}$-weekly temperature effect maps for the 2001-2010 period. For each year, maps of the week of temperature effect peak occurrence and, both the total and consecutive number of weeks per year with temperature above $\mathrm{T}_{\text {opt }}$ were created. The yearly maps were then combined into a decadal map by calculating the average and standard deviation. A proxy of time lag between suitable $\mathrm{T} 2 \mathrm{~m}$ periods (Dsuit consec $_{\text {) }}$ was defined to identify the proportion of consecutive over the total suitable time periods for vector development (Eq. 1):

Dsuit $_{\text {con sec }}=\frac{\text { Wsuit }_{\text {total }}-\text { maxWsuit }_{\text {con sec }}}{\text { Wsuit }_{\text {total }}}$ where, maxWsuit $_{\text {consec }}$ was the period with largest number of consecutive suitable weeks per year and Wsuit $_{\text {total }}$ was the total number of suitable weeks per year. All areas with less than one suitable week per year were considered unsuitable for An. atroparvus development.

The second approach consisted in generating maps of potential maximum VD by coupling larval habitat and temperature suitability (see Section 2.4.1), thus accounting for their interaction. Previous sitelevel relationships, established between VD and larval habitat suitability, were extrapolated to the entire Portuguese mainland territory. The temperature dataset was re-sampled, using the nearest neighbour algorithm, from $1 \mathrm{~km}$ to $250 \mathrm{~m}$ and linearly interpolated to fill in the existing $\mathrm{T} 2 \mathrm{~m}$ gaps. The analysis was conducted per type of habitat drivers, i.e. only static or both static and dynamic (see Section 2.4.1). For the latter case, the extrapolation was done for the largest consecutive period with temperature above $\mathrm{T}_{\mathrm{opt}}$ assuming that the higher the number of weeks with optimum temperature, the highest the suitability for vector development.

To distinguish between areas with high and low temperature suitability, an additional empirical variable was created. For each year and each pixel, the number of weeks with optimum T2m was divided by the maximum number of suitable weeks in the entire study area for a given year, resulting in a temperature-limiting factor varying between 0 and 1 , which reflects the low and high annual growing length suitability of vector development, respectively. This was done separately for the total and consecutive number of weeks with temperature above $\mathrm{T}_{\text {opt }}$. The yearly potential maximum VD for each year was defined as the estimated maximum VD multiplied by the growing length suitability. Finally, a decadal map was generated by calculating the mean and standard deviation of the yearly maximum VD maps.

\section{Results}

\subsection{Vector density dynamics}

Monthly values of vector density for the four different study regions are presented in Fig. 2, showing a remarkable seasonality, as expected. Comporta, the most frequently surveyed site (see Table 1 and Supplement), presents the highest An. atroparvus densities.

In Comporta, densities were high for about three months in the entire year, increasing in June, peaking in midsummer and slowly decreasing up to October/November. In Alqueva, the main peak occurred in spring (May, June) and a lower peak occurred in autumn (around October). In the summer, VD was consistently low although few exceptions occurred. In Algarve, due to different sampling frequencies, lower number of samples and the wider range and variability of larval habitat suitability surrounding the sampling sites, the intra annual patterns are not as evident as in Comporta and Alqueva. At Centre-West Algarve, VD seasonality presents medium-high values between May and September, with high inter-site variability. In East Algarve, the VD seasonality was similar to the one in Alqueva, with two yearly peaks, before and after summer.

\subsection{Larval habitat suitability}

When simple linear relationships were used to define larval habitat suitability, the land cover suitability, EVI and distance to breeding sites individually explained 53,40 and $31 \%$ of the maximum VD variability, respectively. More than $70 \%$ of the sites had maximum VD values captured in periods of $\mathrm{T} 2 \mathrm{~m}$ above the empirical $\mathrm{T}_{\text {opt }}$ threshold.

The assessment of non-linear multi-variable models showed that the exponential equation consistently yielded the best agreements for the estimation of maximum VD. Model performance was higher for lower temporal lags and increased with the buffer radius up to distinct MEF peaks (Fig. 3). Two different interactions between larval habitat drivers and maximum VD were observed: up to $2500 \mathrm{~m}$, the equations using static data combining land cover and distance to optimum 

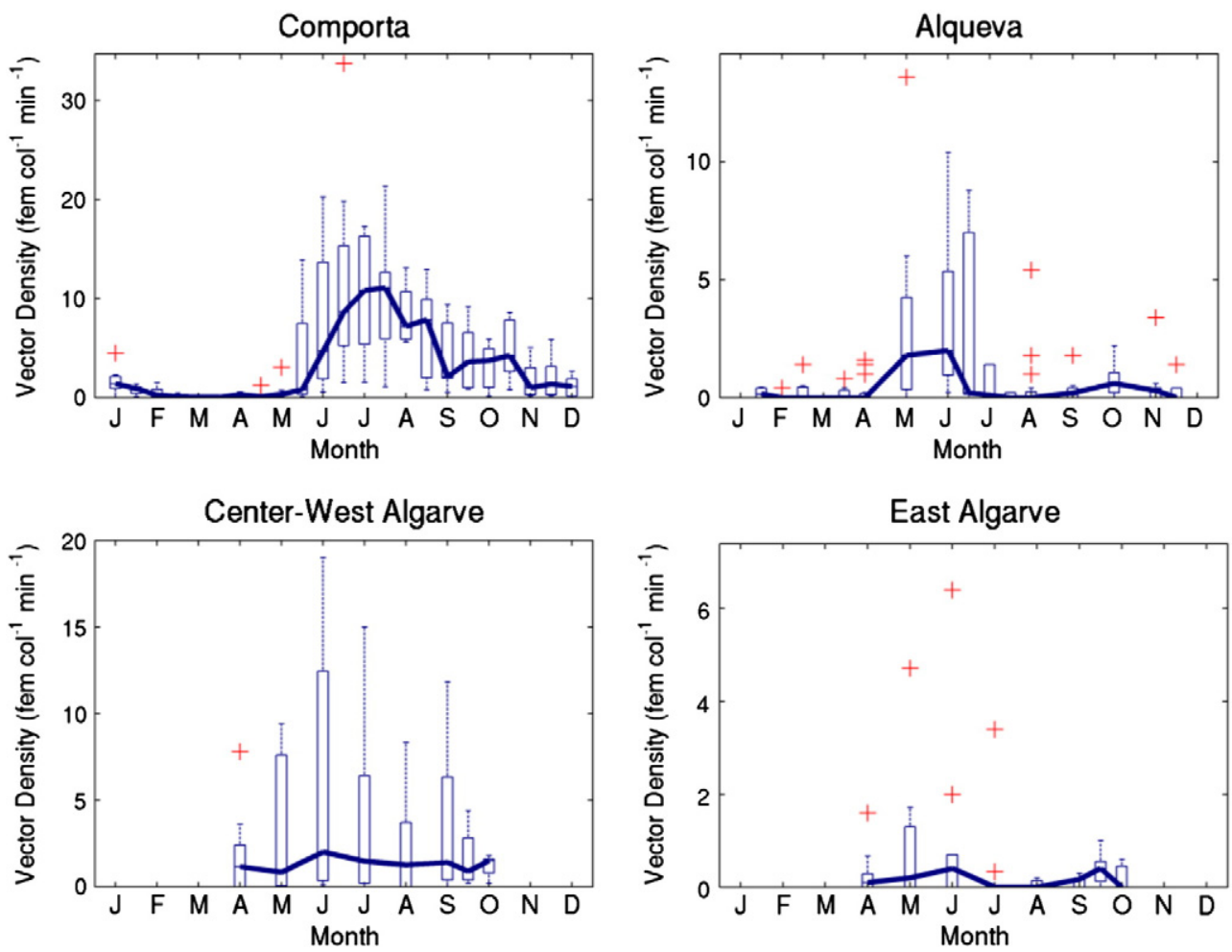

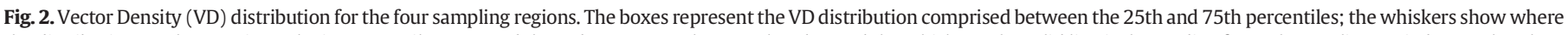

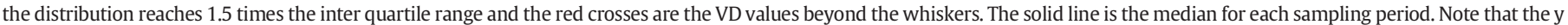
axis has a different scale for each sampling region, in order to show properly the low values.

breeding sites had the best performance, while above $2500 \mathrm{~m}$, the best performance was achieved with the combination of land cover and dynamic vegetation data.

Using the static data approach, maximum VD was directly related to the presence of suitable land cover and inversely related with the distance to optimum breeding sites (Fig. 4a). The high model agreement $(\mathrm{MEF}=0.84)$ suggests that static landscape variables are the most important factors driving maximum VD at each sampling site. When coupling static land cover suitability with dynamic vegetation data, the best agreement was found for EVI acquired the week prior to the maximum VD's sampling date (MEF $=0.90$, Fig. 4b). Integrating EVI improved the cases of underestimation of maximum VD (e.g. Alqueva sites 10 and 11 in Fig. 4). It is also noteworthy to mention that, when coupled with land cover suitability, NDWI and NDVI also yielded good

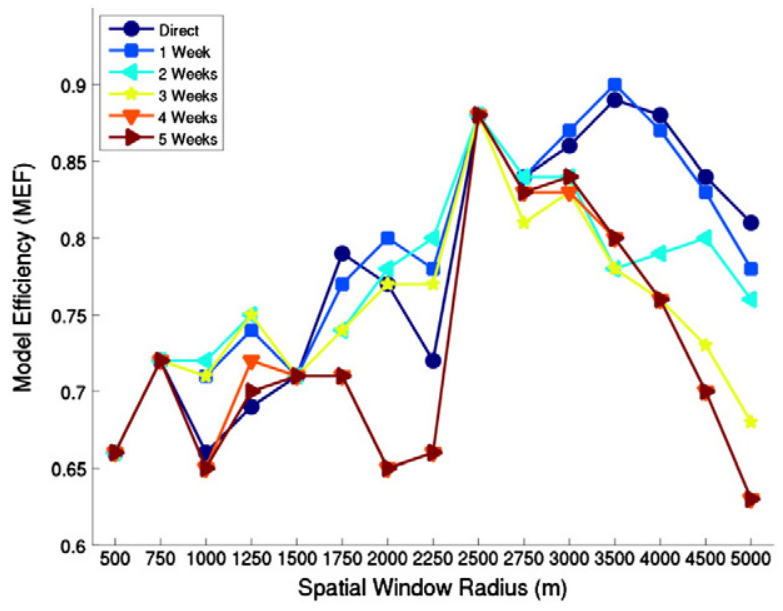

Fig. 3. Highest MEF distribution for larval habitat suitability estimation according to different temporal lags and spatial buffer radius, considering data from all sites. agreements $(\mathrm{MEF}>0.80$ ). Although statistical modelling methods enable the extrapolation to unsurveyed areas, predictions outside the range of values of the fitted data must be addressed with caution (e.g. Machault et al., 2011). Thus, posterior extrapolations were constrained to the maximum observed VD, i.e. 35 females col. ${ }^{-1}$ min. $^{-1}$.

In conclusion, results indicate that static and dynamic variables related with mosquito larval habitat suitability, especially land cover, distance to breeding sites and EVI, can be used to accurately estimate maximum site-level VDs.

\subsection{Temperature suitability}

\subsubsection{Site-level relationships}

The distribution of all VD estimates against the average T2m for the three larval habitat suitability partitions, as presented in Section 2.4.1, as well as the three best T2m effect models, are presented in Fig. 5. Results show that An. atroparvus abundance was constrained at low and high T2m values, with higher VD values occurring between 19 and $25{ }^{\circ} \mathrm{C}$. However, some relatively high-density values, not exceeding 10 females $\mathrm{col}^{-1} \mathrm{~min}^{-1}$, were observed outside the latter T2m range. As expected, for the same T2m values, VDs were higher with increased larval habitat suitability. Partitioning the observed VD according to the dominant host type and region did not show any clear patterns (not shown). For low larval habitat suitability sites, the existence of an optimum temperature range was not evident and higher VD occurred generally for $\mathrm{T} 2 \mathrm{~m}$ above $20^{\circ} \mathrm{C}$.

The calibrated T2m effect models were similar for minimum, average and maximum T2m (not shown) and the use of $\mathrm{T} 2 \mathrm{~m}$ integrated at different spatial buffer radius did not increase the explained variability of VD, which could be explained by the low spatial variability of $\mathrm{T} 2 \mathrm{~m}$. The equations and the calibrated parameters for the three best $T 2 \mathrm{~m}$ effect models are detailed in Table 3. The distribution of the T2m effect models supports the existence of an optimum average T2m around $22{ }^{\circ} \mathrm{C}$ (Fig. 5). Considering the relationship between the maximum 


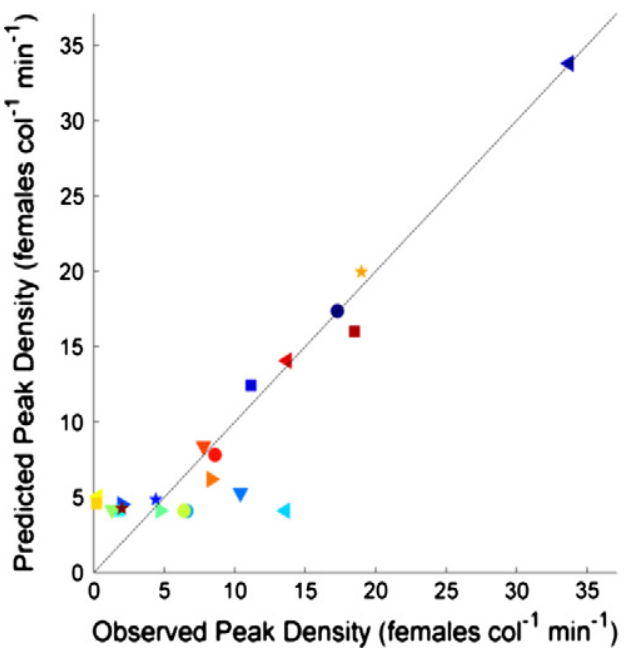

MaxVD $=a+b \times e^{\left(c \times{ }_{p 25} \text { DistBreed }^{2}+d \times{ }_{p 90} L \text { Cover }\right)}$

$\mathrm{a}=4.0961 ; \mathrm{b}=0.5265 ; \mathrm{c}=-0.5721 ; \mathrm{d}=4.5494$

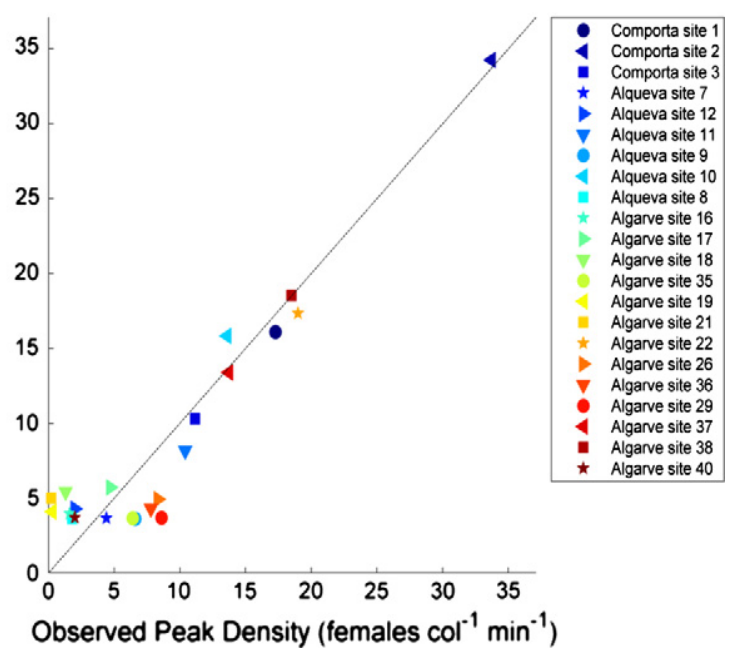

$\operatorname{Max} V D=a+b \times e^{\left(c \times_{\max } E V I^{2}+d \times_{\text {mean }} L C o v e r\right)}$

$\mathrm{a}=3.3577 ; \mathrm{b}=0.0009 ; \mathrm{c}=12.1094 ; \mathrm{d}=12.2942$

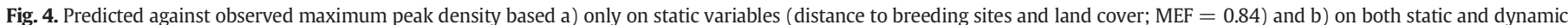

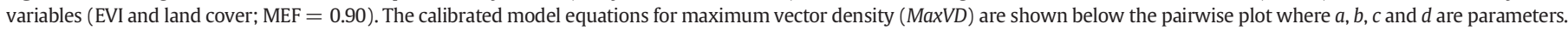
DistBreed is distance to breeding sites and LCover is land cover suitability.

observed VD for each $0.5{ }^{\circ} \mathrm{C}$ interval and the T2m effect models, the Gaussian model had the best performance with $\mathrm{r}^{2}=0.74,0.51$ and $0.30(p<0.05)$ for high, medium and low larval habitat suitability classes, respectively. The model calibration for each individual region did not show significant differences between optimum T2m (not shown), just around $1{ }^{\circ} \mathrm{C}$ higher for Alqueva and East Algarve, the hotter and more arid regions.

The effects of T2m seasonality on VD can be observed in Fig. 6. In Comporta, the pattern was unimodal and high values of T2m effect occurred consecutively from June until the end of September and the $\mathrm{T} 2 \mathrm{~m}$ effect was above $\mathrm{T}_{\text {opt }}$ (see Section 2.4.2) on average during 15 weeks per year. Both Alqueva and East Algarve presented similar bimodal T2m effect patterns with a shorter number of consecutive suitable periods than in Comporta, occurring before and after the summer,

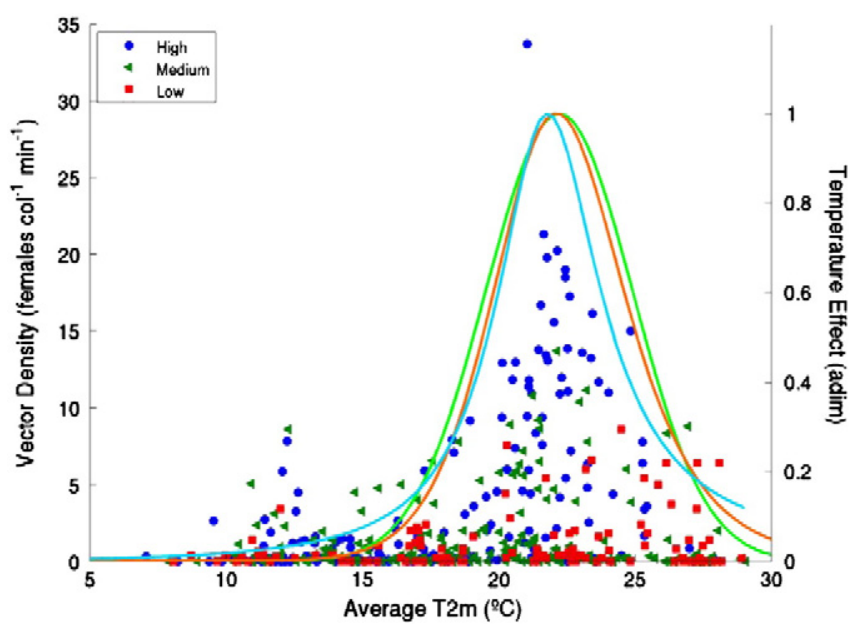

Fig. 5. Vector density distribution and calibrated average temperature limiting effect for the entire range of average $\mathrm{T} 2 \mathrm{~m}$. Vector density is discriminated according to three classes of larval habitat suitability (markers) and the three best temperature effect models are shown in coloured lines: Gaussian (green), Log-logistic (red) and PI curve (blue). i.e. in May-June and September-October. In the summer, average T2m was too high to enable enhanced vector development and the T2m effect was above $\mathrm{T}_{\text {opt }}$ on average during 6 to 8 weeks per year. In Centre-West Algarve, the T2m effect seasonal distribution was between those observed in the other study regions. Variability was relatively high and $\mathrm{T} 2 \mathrm{~m}$ effect was above $\mathrm{T}_{\mathrm{opt}}$ on average during 10 weeks per year. Between June and October, there was low temperature limitation to vector development, although the variability was very high during July and August.

In conclusion, the use of satellite-derived T2m data allowed the establishment of robust quantitative relations between temperature and VD. It seems clear that vector abundance was favoured by average $\mathrm{T} 2 \mathrm{~m}$ between 19 and $25^{\circ} \mathrm{C}$.

\subsubsection{Spatial mapping}

Grid-level extrapolation of T2m effect for vector development shows a North-South gradient regarding the average number of total suitable weeks per year (Fig. 7a). Temperature suitability is low at North, around 4 weeks per year, with the exception of few areas, such as the city of Porto $\left(41^{\circ} \mathrm{N}, 8.7^{\circ} \mathrm{W}\right)$ and the eastern Douro valley $\left(41^{\circ} \mathrm{N}, 7.5^{\circ} \mathrm{W}\right)$, a region where high summer T2m is usually observed. Temperature suitability is much higher at South, mostly above 8 weeks per year. In some areas, such as the city of Lisboa $\left(38.8^{\circ} \mathrm{N}, 9.1^{\circ} \mathrm{W}\right)$, Comporta and western Algarve, $\mathrm{T} 2 \mathrm{~m}$ is suitable for vector development on average for more than 14 weeks per year. A spatial pattern is evident in which temperature suitability increasing from East to West with a posterior slight decrease in some coastal areas. Spatial patterns in southern Portugal are consistent with the VD magnitudes across the four study region (see Fig. 2).

The average number of consecutive suitable weeks per year shows a distinct spatial pattern (Fig. 7b) with the Southwest of Portugal standing as the most suitable region. A clear difference between Southeast and Southwest suitability is explained by the above mentioned T2m gradient, creating two suitable periods per year (see Fig. 6). Two regions with about 4 months of consecutive suitable T2m stand out: i) the upstream part of the Sado estuary $\left(38.3^{\circ} \mathrm{N}, 8.5^{\circ} \mathrm{W}\right)$, where the Comporta sites are located, and ii) the surroundings of the Tejo estuary $\left(38.7^{\circ} \mathrm{N}, 9.1^{\circ} \mathrm{W}\right)$, dominated by irrigated agriculture and with high population density. The inter-annual variability (i.e. the standard deviation) of temperature 
Table 3

Calibrated model equations and parameters for the T2m effect.

\begin{tabular}{|c|c|c|c|c|c|c|c|c|c|c|}
\hline \multirow[t]{3}{*}{ Model equation } & & \multicolumn{9}{|c|}{ Model parameters } \\
\hline & & \multicolumn{3}{|c|}{ Average T2m } & \multicolumn{3}{|c|}{ Maximum T2m } & \multicolumn{3}{|c|}{ Minimum T2m } \\
\hline & & $a$ & $b$ & $c$ & $a$ & $b$ & c & $a$ & $b$ & $c$ \\
\hline$\frac{1}{\sqrt{2 \pi b^{2}}} e^{-\frac{(T-a)^{2}}{2 b^{2}}}$ & Gaussian & 22.212 & 2.675 & - & 27.397 & 3.172 & - & 16.583 & 2.582 & - \\
\hline$\frac{(b / a)(T / a)^{b-1}}{\left[1+(T / a)^{b}\right]^{2}}$ & Log-logistic & 22.347 & 13.804 & - & 22.538 & 13.431 & - & 16.774 & 10.641 & - \\
\hline$\frac{T}{\left(a T^{2}+b T+c\right)}$ & PI curve & 0.047 & -2.145 & 24.569 & 0.0236 & -1.309 & 18.377 & 0.138 & -4.703 & 40.865 \\
\hline
\end{tabular}

$T$ represents the temperature variable in ${ }^{\circ} \mathrm{C} ; a, b$ and $c$ are the calibrated model equations' parameters.

suitability was low in regions with high number of suitable weeks and some low suitability areas (not shown).

In the areas with a moderate-high suitable period length, typically above 10 suitable weeks per year, distinct temporal patterns of temperature suitability are evident (Fig. 8). In the South, the time lag between suitable periods decreases from East to West, increasing again in some coastal areas. The areas with higher total and consecutive suitable periods are located in the Comporta region and its surroundings, particularly northwards up to the Tejo River. In the South, a longitudinal band, between 8 and $9^{\circ} \mathrm{W}$ that extends northwards within the latitudinal range of $37-39^{\circ} \mathrm{N}$, stands out as the most temperature-suitable area for An. atroparvus development. In the North, the temperature suitability was considerably lower decreasing from East, where temperature is typically higher, to West, where the temperature is too low for relevant vector development. However, two areas stand out, namely the upstream part of the Douro valley $\left(41^{\circ} \mathrm{N}, 7^{\circ} \mathrm{W}\right)$ and the city of Porto $\left(41^{\circ} \mathrm{N}, 8.7^{\circ} \mathrm{W}\right)$.

In conclusion, extrapolating the relationships estimated at site-level between VD and satellite-derived T2m allowed describing the spatial
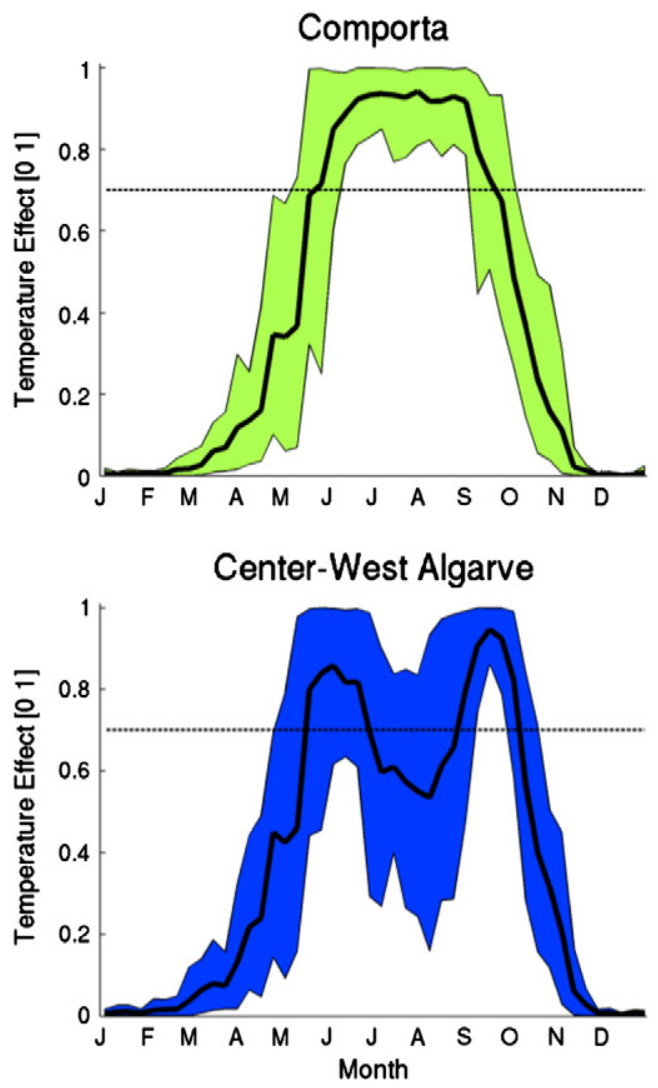

distribution of temperature suitability for vector development in the entire country.

\subsection{Environmental suitability}

\subsubsection{Site-level relationships}

The environmental suitability for mosquito development was characterized by combining the effects of temperature and larval habitat suitability. The interactions between VD and both temperature (absolute and effect) and EVI (percentile 90) at site-level are presented in Fig. 9. The use of EVI (p90) integrated over radii between 1500 and $3500 \mathrm{~m}$, highlighted better the relations between VD and vegetation and showed clearer vegetation-temperature patterns than the remaining vegetation indices. The spatial integration of $\mathrm{T} 2 \mathrm{~m}$ within a spatial buffer retrieved similar results when compared with the single pixel value of the site's location (not shown).

For high and medium suitability classes, most of the higher VD values fell within the $19-25{ }^{\circ} \mathrm{C}$ optimum $\mathrm{T} 2 \mathrm{~m}$ range and were coincident with EVIs higher than 0.3 . The relationship between higher vegetation

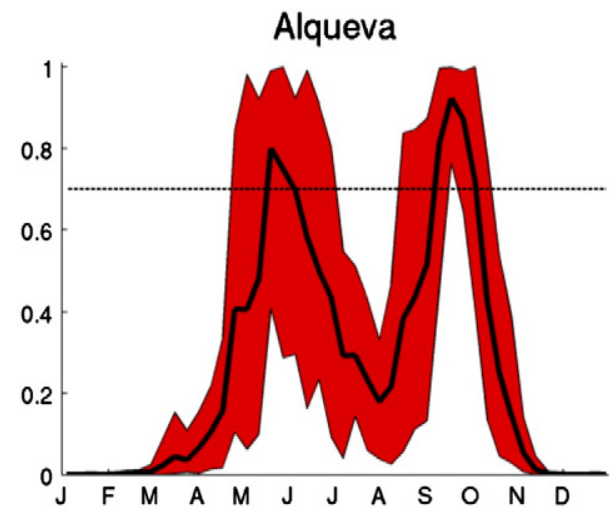

East Algarve

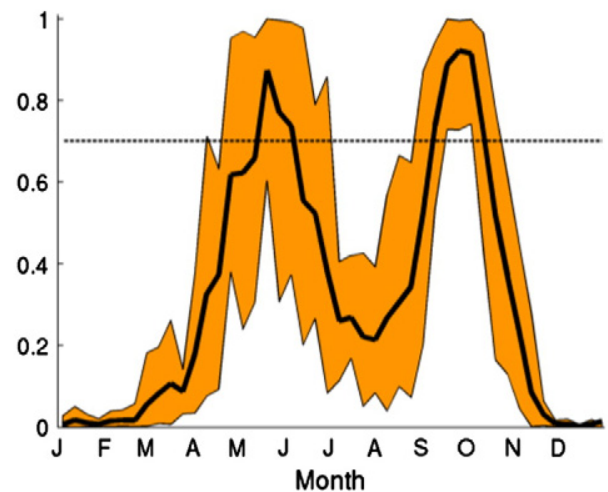

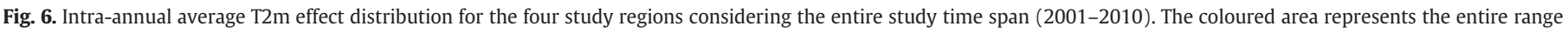

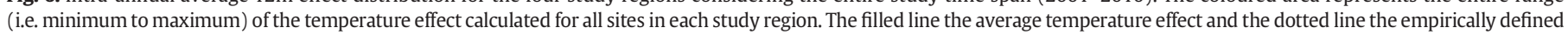
optimum temperature effect threshold. 

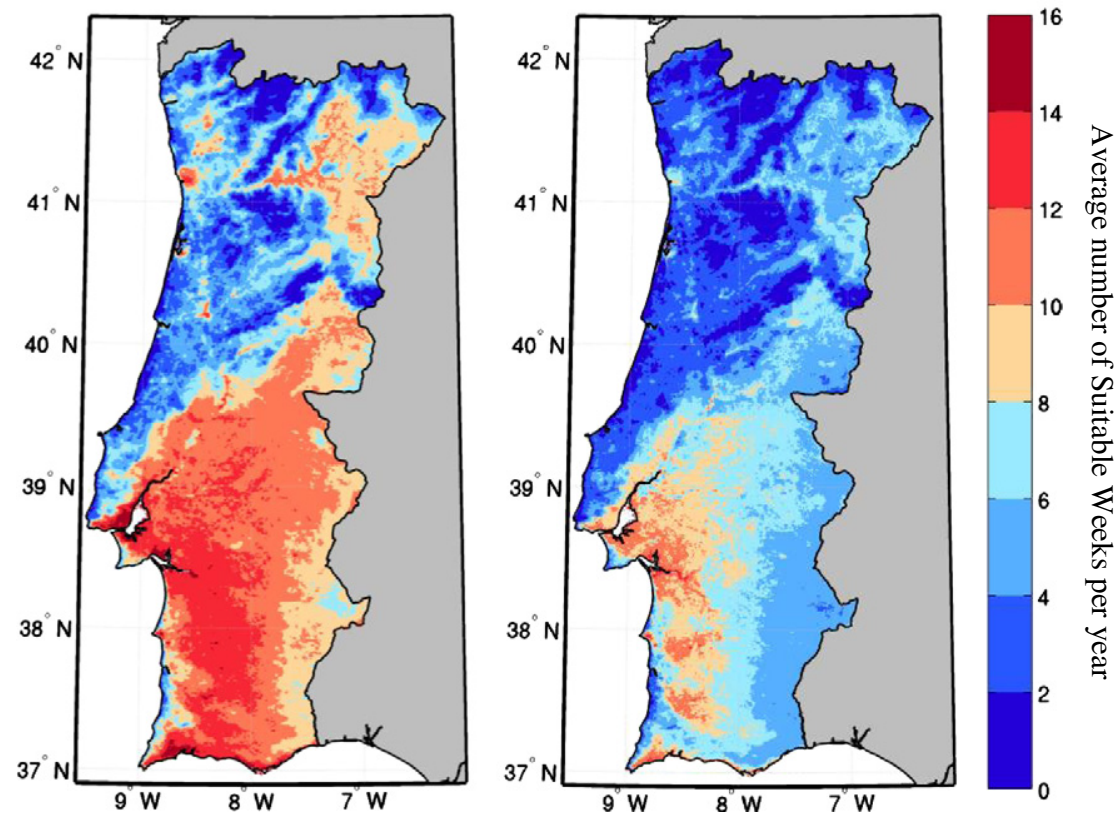

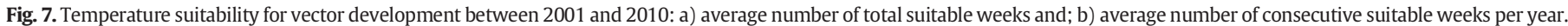

greenness and higher VDs was not independent, showing that observed patterns of VD are explained by the combination between vegetation greenness and optimal T2m. High suitability classes represent ecosystems for which the periods of high vegetation greenness and optimal temperature overlap (Fig. 9a-b upper panel), particularly in late spring and summer, as is the case of permanently irrigated land covers (e.g. rice fields, golf fields) (see also Table 2). Medium suitability classes comprise ecosystems where the temperature-vegetation patterns showed higher variability, with an overall increase of greenness with temperature increase until $20-22{ }^{\circ} \mathrm{C}$ (typically occurring in spring), followed by a decrease of greenness with higher temperature (Fig. 9a-b central panel). In this class, there were cases with higher VDs that also occurred when EVI was high and T2m was in the optimal range. Medium suitability classes mainly included agricultural fields with sporadic or no irrigation during the period of optimal $\mathrm{T} 2 \mathrm{~m}$ for vector development, including orchards, olive groves, agroforestry, and heterogeneous agricultural patterns, as well as some natural vegetation areas. Low suitability sites showed a linearly decreasing temperature-vegetation relation with higher vegetation greenness occurring when temperature was not suitable for vector development, and vice versa (Fig. 9a,b bottom panel), associated to increasing ecosystems' water limitation as the warm and dry season progresses.
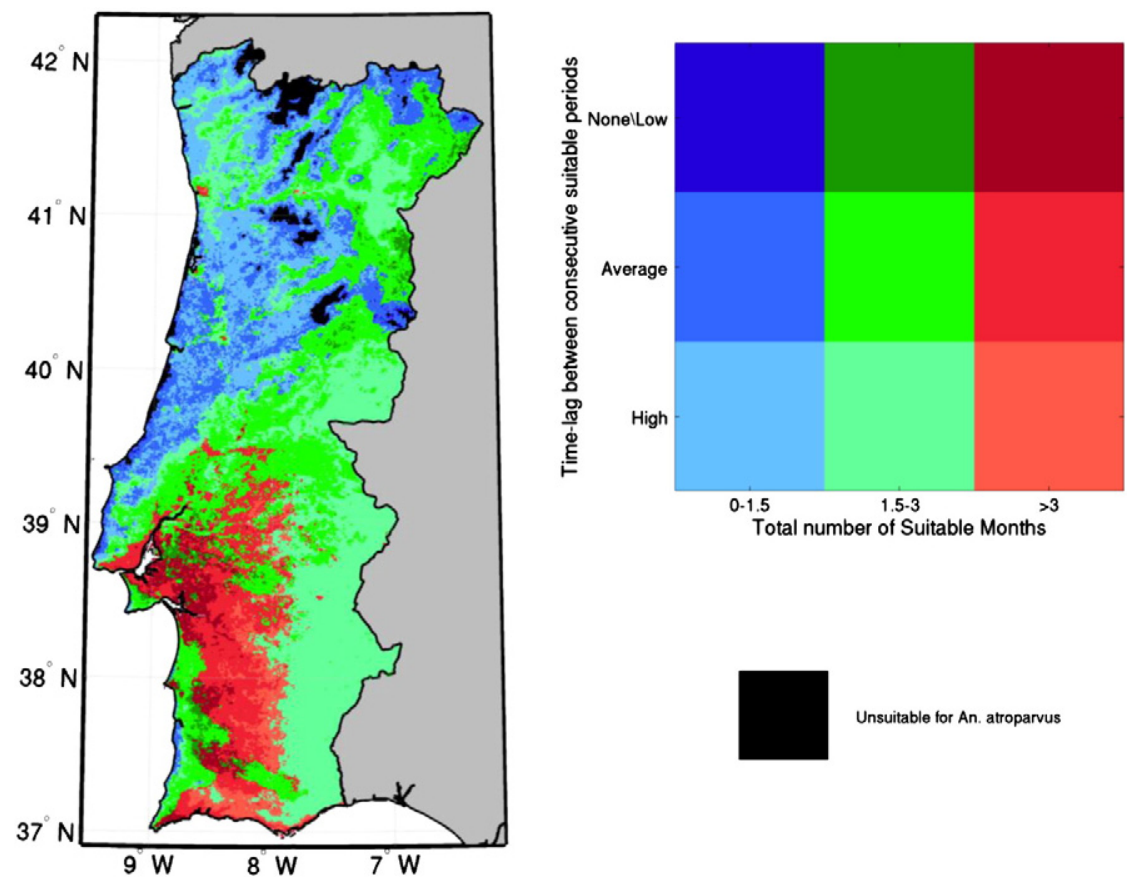

Unsuitable for An. atroparvus

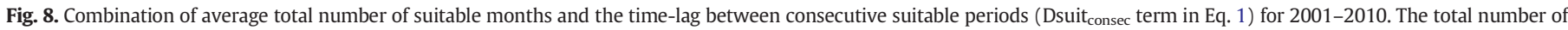

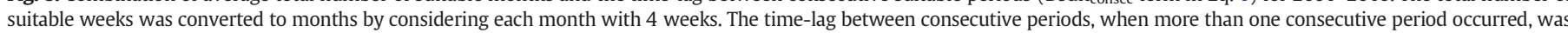
calculated considering only the largest consecutive period. 


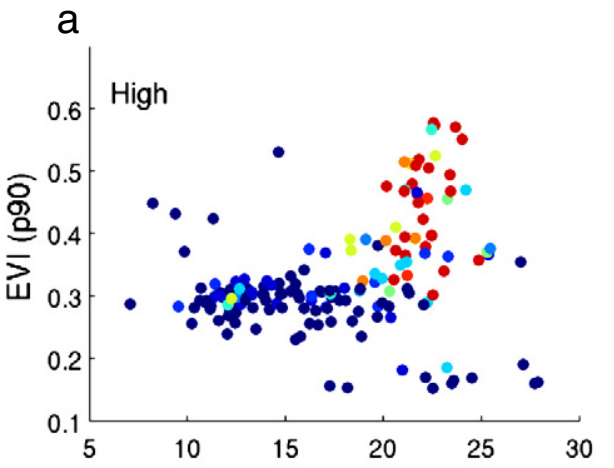

b
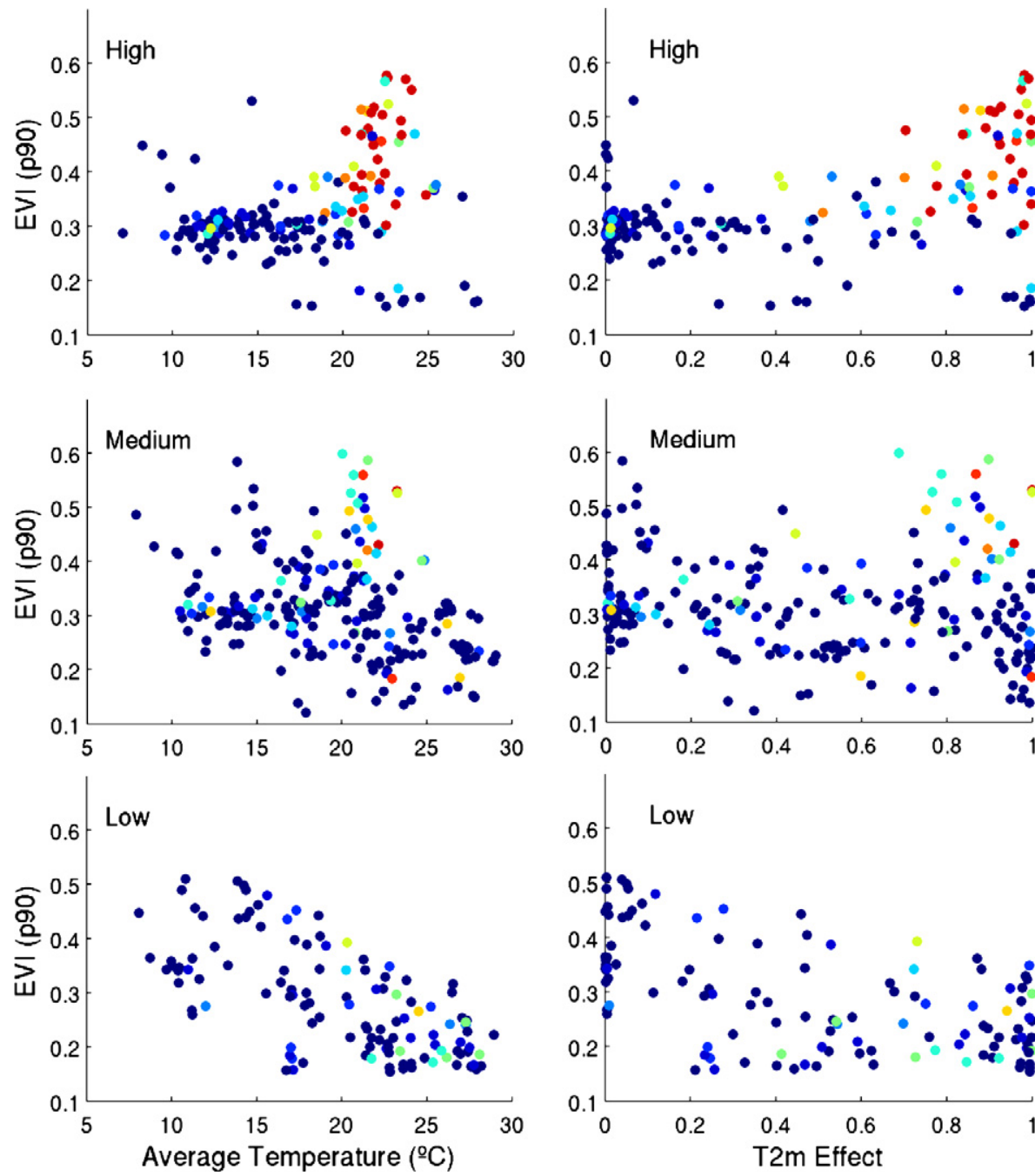
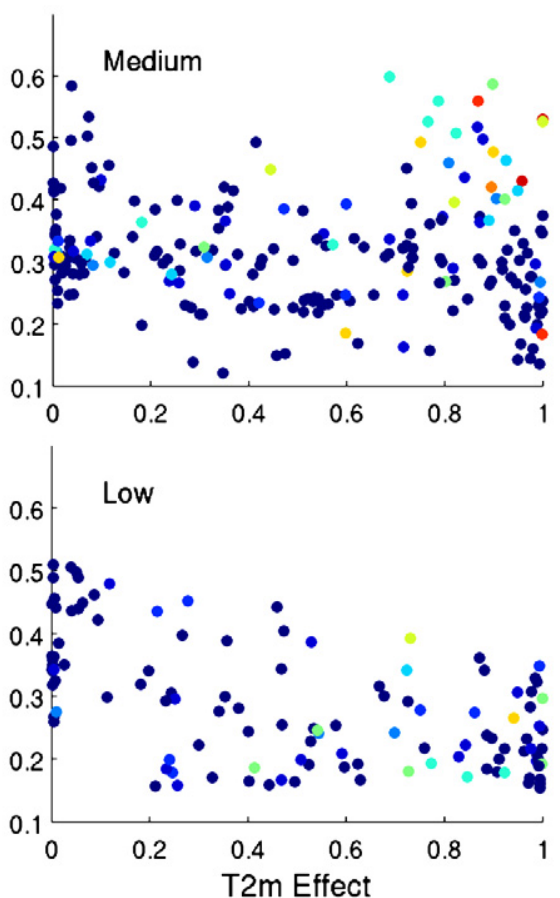

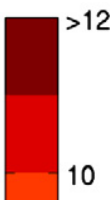

0

Fig. 9. Scatter plots of VD versus T2m and EVI for different larval habitat suitability classes: a) average temperature $\left({ }^{\circ} \mathrm{C}\right)$ and b) average temperature suitability.

In conclusion, high VDs and high larval habitat suitability tend to be related with ecosystems where the high vegetation productivity period coincides with the optimal temperature interval, generally spring and summer.

\subsubsection{Spatial mapping}

The mapping of the potential maximum VD over the 2001-2010 period was done using static variables (Fig. 10a) and the combination of both static and dynamic variables (Fig. 10b).

The Centre-South of Portugal has more areas with higher maximum potential VD when compared to the North. Some large patches of high maximum potential VD are common for both modelling approaches: the Tejo and Sorraia valleys $\left(39^{\circ} \mathrm{N}, 8.8^{\circ} \mathrm{W}\right)$, the Sado valley $\left(38.3^{\circ} \mathrm{N}, 8.5^{\circ} \mathrm{W}\right)$, the Guadiana river banks near Elvas $\left(38.9^{\circ} \mathrm{N}, 7.1^{\circ} \mathrm{W}\right)$, the Mondego river banks $\left(40.2^{\circ} \mathrm{N}, 8.5^{\circ} \mathrm{W}\right)$, the Odemira $\left(37.5^{\circ} \mathrm{N}, 8.8^{\circ} \mathrm{W}\right)$ and Idanha-a-Nova municipalities $\left(39.9^{\circ} \mathrm{N}, 7.2^{\circ} \mathrm{W}\right)$. All these patches are located in or near extensive irrigated agricultural areas, usually near reservoir systems and/or large rivers. The smaller patches with high potential should not be considered as insignificant, as demonstrated by the high VD values estimated in Comporta and Centre-West Algarve (see Fig. 2).

The combination of maximum potential VD with growing length suitability highlights the regions where both mosquito larval habitat and optimum T2m conditions coincided (Fig. 10c). The region with highest suitability for An. atroparvus development is located between 37.5 and $39.5^{\circ} \mathrm{N}$, with the exception of the South-West coast. Considering the consecutive suitable temperature window period, by comparing Figs. 8 and $10 \mathrm{c}$, it is clear that Sado $\left(38.3^{\circ} \mathrm{N} 8.5^{\circ} \mathrm{W}\right)$ and Sorraia $\left(39^{\circ} \mathrm{N}\right.$ $8.8^{\circ} \mathrm{W}$ ) valleys have the highest suitability in the entire study region.

In conclusion, the grid-based extrapolation indicated that the timing of vegetation development in suitable habitats for mosquito breeding with optimal temperature conditions is important for vector development. Combining and extrapolating these factors allowed the identification of the areas with higher and lower suitability for An. atroparvus development.

\section{Discussion and conclusions}

\subsection{Larval habitat suitability}

The site-level analysis showed that the estimated larval habitat suitability based on land cover and EVI was strongly associated with maximum VD peaks. The presence of irrigated agriculture in the surrounding of the sampling sites was consistent with higher observed VDs, attesting the impact of agricultural activities in Anopheles density (Minakawa et al., 2005; Mutuku et al., 2009). Ninety percent of the maximum VD 
a

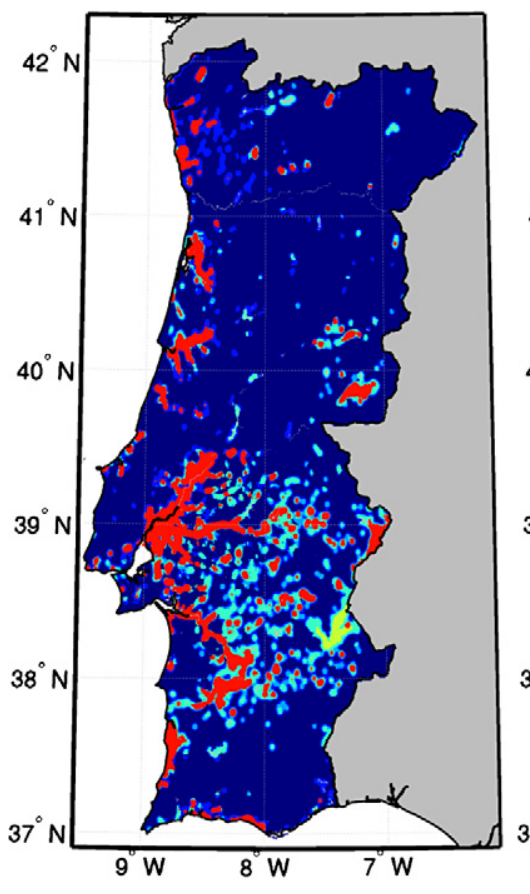

b

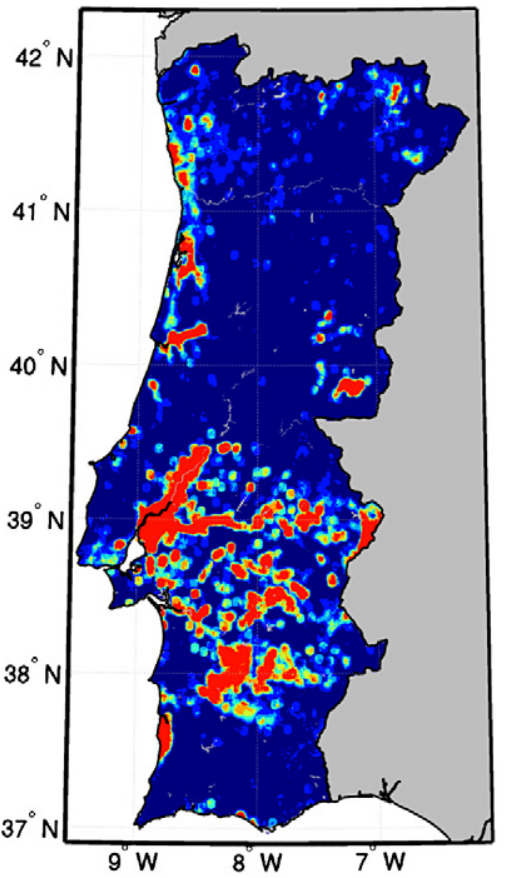

C

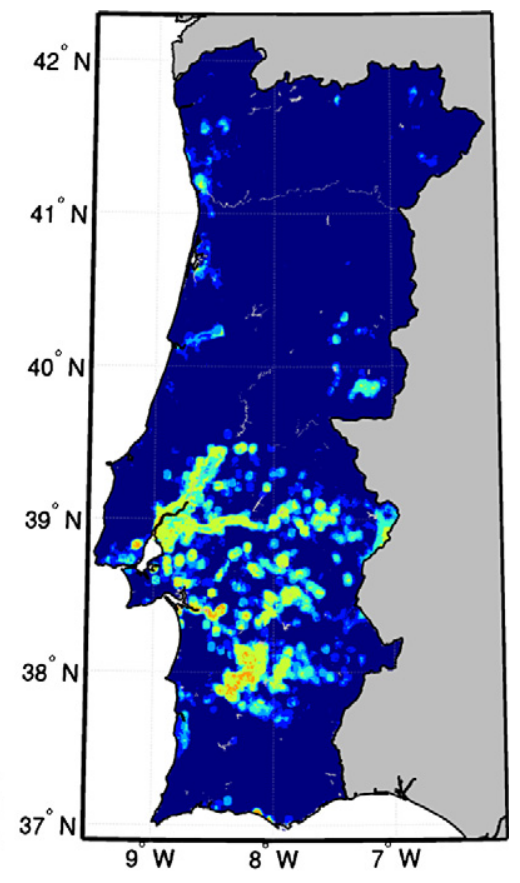

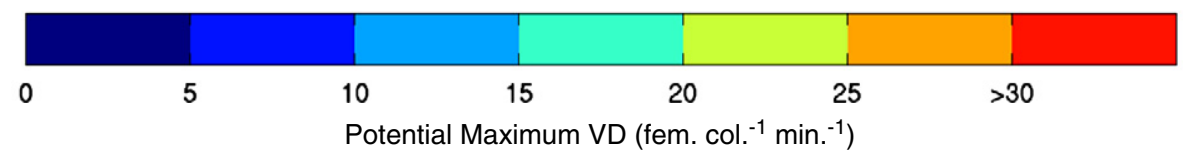

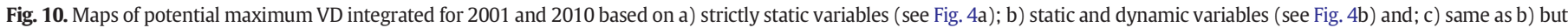
constrained by the average growing length suitability.

variability was explained by a small number of environmental variables. The land cover suitability and distance to optimal breeding sites were the most relevant factors accounting for more than $80 \%$ of the variability. The integration of dynamic vegetation data strengthened the predictive accuracy of our modelling approach, particularly in sites prone to VD underestimation. These results highlight the importance of combining land cover and vegetation state information to describe the larval habitat suitability of An. atroparvus.

Model accuracy was consistently higher when relevant variables were spatially integrated through the use of circular spatial buffers with two distinct peaks $2500 \mathrm{~m}$ and $3500 \mathrm{~m}$. Both were significantly larger than previously reported by other authors for rice fields' habitats (e.g. Cailly et al., 2011; Lourenço et al., 2011; Romi et al., 2012; Tran et al., 2008). This difference can be explained by the narrow spatial structure of rice fields and other irrigated agricultural areas, typically located along river/estuary beds, which leads to higher correlations for smaller spatial radius. The land cover heterogeneity in a buffer, along with the relative contribution of the suitability of each class, was of great importance and was captured by the percentile 90 of land cover suitability statistic. These differences highlighted the importance of sampling areas with different landscape characteristics in order to account for the influence of spatial heterogeneity.

The achieved optimal spatial buffer radii are well within the reported flight range of An. atroparvus (Cambournac \& Hill, 1938; Kaufmann \& Briegel, 2004; Tran et al., 2008). Results suggest that, when females have food available nearby, the flight range tends to be smaller. The host type, presence and its abundance may also have influenced the determination of the larval habitat suitability. This aspect can be one of the reasons behind the lower agreements in sampling sites with maximum VDs lower than 5 females col. ${ }^{-1} \mathrm{~min}^{-1}$.
Results showed that satellite derived vegetation indices acquired between 8 and 16 days before vector sampling were consistently more correlated with maximum VDs. This period is within the range of days reported as the duration of larval development (15-20 days) at optimum temperature conditions for An. atroparvus in Southern Portugal (Cambournac \& Hill, 1938; WHO, 1982).

Larval production is a function of complex interaction of several habitat factors (Shililu et al., 2003) some of which cannot be captured through satellite data. Local-scale factors that may influence VD, such as water quality, sun exposure, characteristics of the agricultural facilities, the presence or absence of animal hosts, host species, and local sub-pixel landscape characteristics were not considered (Capinha et al., 2009; Hutchinson, 2004; Minakawa et al., 2005). However, the results obtained suggest that local scale factors have low impact on explaining VD peaks and are probably more relevant in locations presenting low An. atroparvus densities. Additionally, it should be referred that the sampling frequency, choice of the surveyed facilities and weather-related factors (e.g. wind) might have limited the acquisition of some VD peaks.

Although valuable information was retrieved for the larval habitat suitability, it is important to recognize its limitations and how these can be addressed in future work. Firstly, quantifying the suitability based on descriptive information collected in literature and prior knowledge may introduce high uncertainty. As an example, Sinka et al. (2010) pointed out the uncertainty associated with the preference of $A n$. atroparvus for fresh or brackish waters, consistent with the wide spread of salt concentration tolerated by this species found in literature (Bates \& Hackett, 1938; Hackett \& Missiroli, 1935; Hutchinson, 2004). Secondly, using a generic land cover classification in which the same class can have very different characteristics under different contexts encloses important limitations. However, the use of satellite-derived vegetation 
data significantly contributed to the attenuation of the uncertainty mentioned above. Thirdly, alternative modelling approaches more suitable for ecological studies, such as generalized linear models, should be explored in the future (O'Hara \& Kotze, 2010). However, the very good model adjustment attained in this work suggests that our modelling approach is robust, contrary to the findings of the former authors. Finally, the spatial-temporal characteristics of larval sites should be more accurately defined, for instance, by using high resolution satellite data (e.g. Dambach et al., 2009; Mushinzimana et al., 2006; Stoops et al., 2008) and including information about the existence of permanent or periodical flooding (Pope et al., 1994; Soti et al., 2009). Although larval habitats may not be directly detectable through remote sensing, satellite data can be used as a proxy to identify land covers where habitats are likely to occur (e.g. Minakawa et al., 2005; Mutuku et al., 2009).

\subsection{Temperature suitability}

The relations between temperature and VD showed the existence of an optimum T2m range for An. atroparvus development between $13-19{ }^{\circ} \mathrm{C}, 19-25^{\circ} \mathrm{C}$, and $24-30{ }^{\circ} \mathrm{C}$ for minimum, average and maximum $\mathrm{T} 2 \mathrm{~m}$, respectively. The calibrated temperature effect models showed that the optimum T2m was described by a unimodal distribution stressing the importance of considering both lower and upper $\mathrm{T} 2 \mathrm{~m}$ constraints on vector population. Density values increased with temperature up to a point when it may be assumed that adult mosquito survival was probably limited by high temperature (see Fig. 6), in agreement with the unimodal temperature dependence of biochemical reactions' kinetics (Chapra, 1997). Kuhn et al. (2002) also showed the existence of lower and upper $\mathrm{T} 2 \mathrm{~m}$ limitations for An. atroparvus development but presented a lower optimum range than the one found in this work. Although results are not directly comparable, because those authors used vector presence and not density values, the differences are probably justified by the coarse climatic dataset used and the inclusion of regions other than Portugal. Mosquitoes sampled in regions with different $\mathrm{T} 2 \mathrm{~m}$ patterns and the use of an accurate, fine-scale satellite-based T2m dataset (Benali et al., 2012) were essential to achieve the results presented in this work. However, the comparison with the work of Kuhn et al. (2002) suggests that future work should extend the study of these relationships to different climatic areas where $A n$. atroparvus is also present.

In a high larval suitability site located in Comporta, density values between 2 and 9 females col. ${ }^{-1}$ min. $^{-1}$ coincided with low modelled optimum T2m conditions (Fig. 5). During low-temperature periods An. atroparvus rests inside warmer animal shelters and feeds periodically, if a host is present, but without laying eggs (Hutchinson, 2004). These two facts, together with small scale variability due to the number and type of hosts and the shelter's characteristics (Capinha et al., 2009), can explain the higher values observed at low temperature. However, errors in the satellite-derived T2m dataset cannot be excluded as a potential cause, since its accuracy is lower in coastal areas (Benali et al., 2012). Model performance was also affected by the unbalanced inter-region distribution of samples that introduced a small bias in the calibration of the T2m effect models. About 40\% of the data was sampled in Comporta, where the temperature is typically mild throughout the year, which led to a slightly lower optimum $\mathrm{T} 2 \mathrm{~m}$ value estimation. We assume that if the vector samples were evenly distributed, the optimum range would probably be slightly higher. Nevertheless, the shape of the T2m effect curve was supported by the observed VD distribution (Figs. 2 and 5). These results highlight the importance of performing vector collections over a wide spatial range with different $\mathrm{T} 2 \mathrm{~m}$ seasonality and magnitude, as well as in locations with different larval habitat suitability.

The temporal distribution of the temperature effect had two distinct seasonal patterns in the four study regions. Firstly, a unimodal timewindow with several consecutive suitable weeks per year, when combined with spring-summer irrigated agriculture, like in Comporta, lead to consistently high VD values from June to September (see Fig. 2).
Secondly, a bimodal temperature suitability window, occurring usually before and after summer, in which high summer temperature probably decreased vector survival limiting its development (Cambournac \& Hill, 1938), like in East Algarve and Alqueva. These different temporal patterns of the temperature effect closely follow the seasonality of $\mathrm{T} 2 \mathrm{~m}$, particularly in areas where $\mathrm{T} 2 \mathrm{~m}$ is too low and/or where the summer is too hot for optimal vector development. The seasonality of the temperature effect was also influenced by the $T_{\text {opt }}$ parameter which was set to reflect conditions were vector development was not significantly limited by $\mathrm{T} 2 \mathrm{~m}$. Although $\mathrm{T}_{\mathrm{opt}}$ was empirically defined, no VD values above 10 females col. ${ }^{-1}$ min. $^{-1}$ were coincident with a $\mathrm{T}_{\mathrm{opt}}$ below 0.7 (Fig. 9b) and about 70\% of the sites had their maximum VD above 0.7 (not shown).

As expected and supported by literature, temperature suitability in the South of Portugal was much higher than in the North, where vector development was probably constrained by the lower $\mathrm{T} 2 \mathrm{~m}$, consistent with the decrease of T2m with increased latitude (e.g. Benali et al., 2012). A large area stood out in the Northeast of Portugal, the upstream part of the Douro valley, that was an endemic malarial area in the past (Bruce-Chwatt \& Zulueta, 1977; Cambournac, 1942). Temperature suitability also showed a longitudinal gradient, reflecting the positive $T 2 \mathrm{~m}$ magnitude and amplitude gradient from coastal to interior regions, due to the dampening effect of the ocean on T2m (e.g. Benali et al., 2012).

The spatial distribution of temperature suitability greatly resembles the previous malaria distribution (Cambournac, 1942, see Fig. 3 in Capinha et al., 2009; Bruce-Chwatt \& Zulueta, 1977). However, the comparison between habitat suitability presented by Capinha et al. (2009; see Fig. 2) and temperature suitability developed in this work (Fig. 5) shows significant differences in the Southeast of Portugal. The inclusion of an upper $\mathrm{T} 2 \mathrm{~m}$ limit is probably the main reason for those differences, since it was the only region in Portugal where extreme temperature in the summer may consistently constrain vector development.

The comparison between VD and the seasonal distribution of temperature suitability at site-level (Figs. 2 and 6) showed that densities were higher in sites with higher consecutive suitable periods. This raises an interesting question about the ecology of An. atroparvus that should be addressed in future research. Clearer insights on the impact of consecutive suitable periods on vector density will be relevant to understand the response of vector dynamics to future temperature changes projections.

Although other authors have previously used satellite-derived climatic surrogates to map the range of malaria vectors (e.g. Lindsay et al., 1998), the use of accurate satellite-derived air temperature data is a novelty. This data set can depict local temperature variations, which are not captured using sparse climatic data (Zhou, Minakawa, Githeko, \& Yan, 2004), therefore improving the accuracy of spatial vector modelling.

It is noteworthy to discuss the impact of two other climatic variables that are relevant for mosquito development and which were not included in this work. Relative humidity influences mosquito survival by affecting its internal water balance and is thermodynamically related to temperature. Longevity is lower at humidity extremes and generally higher with increased humidity within the suitable humidity range (e.g. Service \& Townson, 2002; WHO, 1982). Rainfall affects mosquito density directly due to the formation of breeding sites and indirectly due to the increase in relative humidity (e.g. Mushinzimana et al., 2006). In regions where surface water availability is not directly dependent on rainwater, rainfall is probably not a relevant factor (Service \& Townson, 2002). Anopheles atroparvus is known to breed in a wide range of habitats which are not closely dependent on rainwater (Sinka et al., 2010). In fact, Paaijmans, Wandago, Githeko, and Takken (2007) showed that high rainfall intensities can have a negative impact on VD by flushing its immature stages. The uncertainties about the impact of these climatic drivers and absence of reliable and accurate datasets of rainfall and relative humidity justify their non-inclusion in the present analysis. Moreover, rainfall and temperature are out of phase under Mediterranean water-limited 
environments. However, future work must aim at better understanding the relative impact of both variables on An. atroparvus development.

\subsection{Environmental suitability}

The partition of larval habitat suitability classes highlighted different environment-mosquito site-level relationships. For high and medium larval habitat suitability sites, the temperature-dependence of VD was clear with a noticeable VD increase with EVI increase in the optimum T2m range (Lourenço et al., 2011). For low suitability sites, the optimum $\mathrm{T} 2 \mathrm{~m}$ range was wider and the temperature-dependence was less clear. Results suggest that $\mathrm{T} 2 \mathrm{~m}$ has low relevance in vector development when VD is primarily constrained by low suitable breeding conditions. These relationships must be considered only as indicative of the generic unimodal shape of the temperature influence since mosquitoes are influenced by fine-scale micro climate conditions, such as sun exposure and local variations in temperature due to the presence of vegetation and water (e.g. Minakawa et al., 2005; Pires et al., 1982). Nevertheless, considering the global objective of this study, the role and interplay of macro-scale factors favouring higher VDs were clearly identified.

The temperature/vegetation domain has been used by several authors to characterize ecosystems and derive environmental parameters (e.g. Sandholt, Rasmussen, \& Andersen, 2002). The vegetation indices were used with the assumption that in typical dryland Mediterranean systems, higher values in the summer are indicative of irrigated surfaces. Results showed that under these conditions, VDs tend to be high. On the other hand, in semi-arid non-irrigated ecosystems, where there was a marked linearly decreasing temperature-vegetation relation, VDs were usually low. These occur in natural Mediterranean ecosystems, winter crops and pastures, where vegetation productivity is concentrated in the winter wet season (see e.g. Sandholt et al., 2002). In such cases, there was a clear shift between high vegetation index values and optimal $\mathrm{T} 2 \mathrm{~m}$; vegetation indices did not increase during the optimal $\mathrm{T} 2 \mathrm{~m}$ range. Some sites had intermediate conditions and were mainly classified as having medium habitat suitability surrounded by areas presenting short periods of high vegetation index values concomitant with the optimum $\mathrm{T} 2 \mathrm{~m}$ range. This reflects the typical seasonal vegetation growth pattern in water-limited Mediterranean regions, with a synchronized spring increase in vegetation cover and temperature, until soil moisture is depleted, followed by a summer dry season during which vegetation growth is severely limited (e.g. Evrendilek \& Gulbeyaz, 2008; Joffre, Rambal, \& Ratte, 1999; Melendez-Pastor, Navarro-Pedreño, Koch, Ignacio Gómez, \& Hernández, 2010).

Environmental suitability mapping allowed the identification of some regions with high potential maximum VD, mainly located within, or nearby, extensive irrigated agricultural fields. By comparing the former malaria distribution in Portugal (Cambournac, 1942; see Fig. 3 in Capinha et al., 2009) with the potential maximum VD maps (Fig. 10), we could assess that the majority of the areas coincide, supporting the findings of Capinha et al. (2009). An exception is the upper Douro Valley, although temperature conditions are suitable in that region. We hypothesize that land cover or agricultural practices have changed in the past 50 years, with extensive land abandonment and afforestation (Jones, de Graaff, Rodrigo, \& Duarte, 2011), which may have led to changes in habitat suitability.

The ongoing expansion of the irrigated area supported by the Alqueva dam can potentially create more suitable conditions for mosquito development. A brief inspection of the NDVI maps between 2001 and 2007 in this region shows an increase of areas with high vegetation productivity during Spring-Autumn, consistent with the gradual expansion of the irrigated perimeter around the dam. In fact, most of the highest densities in Alqueva occurred in 2007. Thus, the above mentioned vegetation, temperature and VD relations can be considered valid for sites with high and medium habitat suitability, where periodical irrigations coincide with the optimum temperature period(s) for vector development.
The suitability for vector development is better assessed by using temperature and mosquito breeding conditions in conjunction. The use of dynamic satellite-based vegetation indices along with land cover information is a novelty and results showed it improved the estimation of environmental suitability for vector development, when compared with using solely land cover data. Although both approaches showed similar patterns, due to the use of a common land cover suitability variable, some relevant differences should be underlined. In agricultural areas, the use of a dynamic vegetation index during the optimal $\mathrm{T} 2 \mathrm{~m}$ period highlights the location of summer crops, while the static approach described only broad agricultural classes. Additionally, water bodies without suitable vegetation nearby presented high larval habitat suitability in the static approach, but low in the dynamic approach. Moreover, satellite-based vegetation indices can also reduce the impact of uncertain empirical larval habitat scoring and land cover change or misclassification, particularly in agricultural classes which play a very important role in An. atroparvus density distribution. Dynamic vegetation variables can be used in future work to assess the potential impact of changing agricultural practices and/or land use on the suitability of vector development.

As mentioned previously, the exponential equation to model the maximum VD has clear limitations when applied outside the calibration conditions. Therefore, its application should be addressed with caution due to the fact that under certain conditions the equation can generate unrealistic high values of potential maximum VD. Thus, the resulting map should be considered as an indicator of the potential maximum VD, highlighting the areas of potentially high, medium and low VDs, and could potentially be used as an indicator of risk of malaria resurgence.

This work pointed out the relative importance of environmental factors and how they interplay, contributing to improve the state-ofknowledge about vector ecology. It does not state that malaria risk has increased or that it will be reintroduced in Portugal, since this depends on several other factors not explicitly considered here. Confusing modelling results with reality would be incorrect. Results can be used to plan vector sampling, identifying areas with higher risk of malaria resurgence and prioritize preventive vector control measures in the future (Shililu et al., 2003; Shroeder \& Schmidt, 2008). Additionally, this work may contribute to a better definition of a well-established method to determine malaria risk, the basic reproduction rate $\left(R_{0}\right)$ and to understand the potential risk of malaria resurgence in European countries (Lindsay et al., 2010).

Given the widespread dissemination of remote sensing data, the conceptual approach presented here can be potentially applied to other regions of the world. Nevertheless, application to other regions needs to be assessed with in-situ data. The knowledge of An. atroparvus bionomics would greatly benefit from studying areas with different climatic conditions and other land covers than the ones present in the surroundings of our sampling sites. Moreover, this methodology may also be used to model other competent European vector species by performing adjustments according to their specific bionomics. The knowledge attained in this work regarding the relationships between An. atroparvus and environmental drivers allows subsequent studies on the past, present and future changes on the vector's spatial and temporal distribution.

Supplementary data to this article can be found online at http://dx. doi.org/10.1016/j.rse.2014.01.014.

\section{Acknowledgements}

This work was funded by the Portuguese Foundation for Science and Technology through the research project MALVEO (contract no. PTDC/CLI/67910/2006) and the post-doctoral fellowship attributed to J.P. Nunes (ref. SFRH/BPD/39721/2007). We acknowledge the MODIS mission scientists and associated NASA personnel for the production of the data used in this research effort. The authors wish to thank the anonymous reviewers for their valuable contribution to this work. 
Additionally, the authors would like to thank the colleagues Artur Santos and Nuno Carvalhais for the insightful discussions. The developed datasets are freely available upon request to aklibenali@gmail.com.

\section{References}

Adamovic, Z. R. (1975). Anopheline mosquitoes (Diptera, Culicidae) recorded in Potisje of the Pannonian Plain. Proceedings of Second European Multicolloquy of Parasitology, Trogir.

Almeida, A., Galão, R., Sousa, C., Novo, M., Parreira, R., Pinto, J., et al. (2008). Potential mosquito vectors of arboviruses in Portugal: Species, distribution, abundance and West Nile infection. Transactions of the Royal Society of Tropical Medicine and Hygiene, 102, 823-832.

Baldari, M., Tamburro, A., Sabatinelli, G., Romi, R., Severini, C., Cuccagna, G., et al. (1998) Malaria in Maremma, Italy. Lancet, 351, 1246-1247.

Bates, M., \& Hackett, L. W. (1938). The distinguishing characteristics of the mosquitoes of Anopheles maculipennis found in southern Europe. Berlin: Congress Entomology, 1555-1569.

Benali, A., Carvalho, A.C., Nunes, J. P., Carvalhais, N., \& Santos, A. (2012). Estimating air surface temperature using MODIS LST data. Remote Sensing of Environment, 124, $108-121$.

Britch, S.C., Linthicum, K. J., Anyamba, A., Tucker, C. J., Pak, E. W., Maloney, F. A., et al. (2008). Satellite vegetation index data as a tool to forecast population dynamics of medically important mosquitoes at military installations in the continental United States. Military Medicine, 173(7), 677-683.

Bruce-Chwatt, L. J., \& Zulueta, J. (1977). Malaria eradication in Portugal. Transactions of Royal Society of Tropical Medicine and Hygiene, 71(3), 232-240.

Cailly, P., Balenghien, T., Ezanno, P., Fontenille, D., Toty, C., \& Tran, A. (2011). Role of the repartition of wetland breeding sites on the spatial distribution of Anopheles and Culex, human disease vectors in Southern France. Parasites and Vectors, 4, 65.

Calheiros, E., Santos, F. D., Calheiros, J., \& Kovats, S. (2006). National assessment of human health impacts of climate change in Portugal: Approach and key findings. Environmental Health Perspectives, 114, 12.

Cambournac, F. J. (1942). Sobre a epidemiologia do sezonismo em Portugal. Lisboa: Sociedade Industrial de Tipografia (235 pp.).

Cambournac, F. J. (1994). Contribution to the history of malaria epidemiology and contro in Portugal and some other places. Parassitologia, 36, 215-322.

Cambournac, F. J., \& Hill, R. (1938). The biology of Anopheles maculipennis, Var. Atroparvus in Portugal. Transactions of the Third International Congress of Tropical Medicine and Malaria, 2. (pp. 178-184).

Capinha, C., Gomes, E., Reis, E., Rocha, J., Sousa, C. A., do Rosario, V. E., et al. (2009). Present habitat suitability for Anopheles atroparvus (Diptera, Culicidae) and its coincidence with former malaria areas in mainland Portugal. GeospatialHealth, 3(2), 177-187.

Castro, L., Cardoso, A., Queirós, L., \& Gonçalves, G. (2004). Malária na Região Norte de Portugal (1993-2002). Caracterização epidemiológica. Acta Médica Portuguesa, 17, 291-298.

Chapra, S.C. (1997). Surface Water-Quality Modeling. McGraw-Hill, Ed., Singapore. ISBN 0-07-011364-5.

Connell, J., McKeown, P., Garvey, P., Cotter, S., Conway, A., O'Flanagan, D., et al. (2004) Two linked cases of West Nile virus (WNV) acquired by Irish tourists in the Algarve, Portugal. Euro Surveillance, 8, 1-2.

Dale, P. E., \& Knight, J. M. (2008). Wetlands and mosquitoes: A review. Wetlands Ecology and Management, 16, 255-276.

Dambach, P., Sié, A., Lacaux, J., Vignolles, C., Machault, V., \& Sauerbom, R. (2009). Using high spatial resolution remote sensing for risk mapping of malaria occurrence in the Nouna district, Burkina Faso. Global Health Action, 2.

Danis, K., Baka, A., Lenglet, A., Van Bortel, W., Terzaki, I., Tseroni, M., et al. (2011). Autochthonous Plasmodium vivax malaria in Greece. Euro Surveillance, 16(42).

EEA (2007). European Environment Agency: CLC2006 Technical Guidelines. Copenhagen.

Evrendilek, F., \& Gulbeyaz, O. (2008). Deriving vegetation dynamics of natural terrestria ecosystems from MODIS NDVI/EVI data over Turkey. Sensors, 8, 5270-5302.

Freitas, F. B., Novo, M. T., Esteves, A., \& de Almeida, A. P. G. (2012). Species composition and WNV screening of mosquitoes from lagoons in a wetland area of the Algarve, Portugal. Frontiers in Physiology, 2, 122.

Gao, B. C. (1996). NDWI-A normalized difference water index for remote sensing of vegetation liquid water from space. Remote Sensing of Environment, 58(3), 257-266.

Green, R. M., \& Hay, S. I. (2002). The potential of Pathfinder AVHRR data for providing surrogate climatic variables across Africa and Europe for epidemiological applications. Remote Sensing of Environment, 79, 166-175.

Hackett, L. W., \& Missiroli, A. (1935). The varieties of Anopheles maculipennis and their relation to the distribution of malaria in Europe. Rivista di Malariologia, 14, 1-67.

Hay, S. I., Packer, M. J., \& Rogers, D. J. (1997). The impact of remote sensing on the study and control of invertebrate intermediate hosts and vectors for disease. Internationa Journal of Remote Sensing, 18, 2899-2930.

Hay, S., Snow, R., \& Rogers, D. (1998). Predicting malaria seasons in Kenya using multitemporal meteorological satellite sensor data. Transactions of the royal society of tropical medicine and Hygiene, 92, 12-20.

Hay, S. I., Tucker, C. J., Rogers, D. J., \& Packer, M. J. (1996). Remotely sensed surrogates of meteorological data for the study of the distribution and abundance of arthropod vectors of disease. Annals of Tropical Medicine and Parasitology, 90, 1-19.

Hutchinson, R. A. (2004). Mosquito-borne diseases in England: Past, present and future risks, with special reference to malaria in the Kent marshes. School of Biological and Biomedical Sciences. Durham: Durham University.

IPCC - Intergovernmental Panel on Climate Change (2007). Fourth assessment report on climate change. In M. L. Parry, O. F. Canziani, J. P. Palutikof, P. J. van der Linden, \& C. E. Hanson (Eds.), Cambridge, UK and New York: Cambridge University Press.
Jetten, T. H., Martens, W. J. M., \& Takken, W. (1996). Model simulations to estimate malaria risk under climate change. Journal of Medical Entomology, 33, 361-371.

Joffre, R., Rambal, S., \& Ratte, J. P. (1999). The "dehesa" system of southern Spain and Portugal as a natural ecosystem mimic. Agroforestry Systems, 45, 57-79.

Jones, N., de Graaff, J., Rodrigo, I., \& Duarte, F. (2011). Historical review of land use changes in Portugal (before and after EU integration in 1986) and their implications for land degradation and conservation, with a focus on Centro and Alentejo regions. Applied Geography, 31, 1036-1048.

Kaufmann, C., \& Briegel, H. (2004). Flight performance of the malaria vectors Anopheles gambiae and Anopheles atroparvus. Journal of Vector Ecology, 29(1), 140-153.

Kuhn, K., Campbell-Lendrum, D., \& Davies, C. (2002). A continental risk map for malaria mosquito (Diptera: Culicidae) vectors in Europe. Journal of Medical Entomology, 39(4), 621-630

Kuhn, K., Campbell-Lendrum, D. H., \& Davies, C. (2004). Tropical diseases in Europe? How we can learn from the past to predict the future. EpiNorth , 5, 6-13.

Lafferty, K. (2009). The ecology of climate change and infectious diseases. Ecology, 90(4), 888-900.

Lindsay, S. W., Hole, D., Hutchinson, R., Richards, S., \& Willis, S. (2010). Assessing the future threat from vivax malaria in the United Kingdom using two markedly different modelling approaches. Malaria Journal, 9, 70.

Lindsay, S. W., Parson, L., \& Thomas, C. J. (1998). Mapping the ranges and relative abundance of the two principal African malaria vectors, Anopheles gambiae sensu strict and An. arabiensis, using climate data. Proceedings of the Royal Society of London, 265, 847-854.

Logan, J.D., Wolesensky, W., \& Joern, A. (2006). Temperature-dependent phenology and predation in arthropod systems. Ecological Modelling, 196, 417-482.

Lourenço, P.M., Sousa, C. A., Seixas, J., Lopes, P., Novo, M. T., \& Almeida, P. G. (2011). Anopheles atroparvus density modelling using MODIS NDVI, in a former malarial area in Portugal. Journal of Vector Ecology, 36(2), 279-291.

Macedo, M. F., Ferreira, J. G., \& Duarte, P. (1998). Dynamic behaviour of photosynthesisirradiance curves determined from oxygen production during variable incubation periods. Marine Ecology Progress Series, 165, 31-43.

Machault, V., Vignolles, C., Borchi, F., Vounatsou, P., Pages, F., Briolant, S., et al. (2011). The use of remotely sensed environmental data in the study of malaria. Geospatial Health, 5(2), 151-168.

Martens, P., Kovats, R. S., Nijhof, S., de Vries, P., Livermore, M. T. J., Bradley, D. J., et al. (1999). Climate change and future populations at risk of malaria. Global Environmental Change, 9, 89-107.

Melendez-Pastor, I., Navarro-Pedreño, J., Koch, M., Ignacio Gómez, I., \& Hernández, E. I. (2010). Land cover phenologies and their relation to climatic variables in an anthropogenically impacted Mediterranean coastal area. Remote Sensing, 2, 697-716.

Mellor, P.S., \& Leake, C. J. (2000). Climatic and geographic influences on arboviral infections and vectors. Revue scientifique et technique (International Office of Epizootics), 19, 41-54.

Minakawa, N., Munga, S., Atieli, F., Mushinzimana, E., Zhou, G., \& Andrew, K. (2005). Spatial distribution of Anopheline larval habitats in western Kenya highlands: Effects of land cover types and topography. American Journal of Tropical Medicine and Hygiene, 73(1), 157-165.

Mushinzimana, E., Munga, S., Minakawa, N., Li, L., Feng, C. C., Bian, L., et al. (2006). Landscape determinants and remote sensing of anopheline mosquito larval habitats in the western Kenya highlands. Malaria Journal, 5, 13.

Mutuku, F. M., Bayoh, M. N., Hightower, A. W., Vulule, J. M., Gimnig, J. E., Mueke, J. M., et al. (2009). A supervised land cover classification of a western Kenya lowland endemic for human malaria: Associations of land cover with larval Anopheles habitats. International Journal of Health Geographics, 8(19).

Nash, J. E., \& Sutcliffe, J. V. (1970). River flow forecasting through conceptual models part I A discussion of principles. Journal of Hydrology, 10(3), 282-290.

O'Hara, R. B., \& Kotze, D. J. (2010). Do not log-transform count data. Methods in Ecology and Evolution, 1, 118-122.

Paaijmans, K. P., Wandago, M.O., Githeko, A. K., \& Takken, W. (2007). Unexpected high losses of Anopheles gambiae larvae due to rainfall. PLOS ONE, 2(11).

Pires, C. A., Ribeiro, H., Capela, R. A., \& da Cunha Ramos, H. (1982). Research on the mosquitoes of Portugal (Diptera: Culicidae) VI. The mosquitoes of Alentejo. Anais do Instituto de Higiene e Medicina Tropical, 8, 79-102.

Pope, K. O., Rejmankova, E., Savage, H. M., Arredondo Jimenez, J. I., Rodriguez, M. H., \& Roberts, D. R. (1994). Remote-sensing of tropical wetlands for malaria control in Chiapas, Mexico. Ecological Applications, 4(1), 81-90.

Reiter, P. (2000). Malaria and global warming in perspective? Emerging Infectious Diseases, $6,438-439$

Ribeiro, H., Pires, C., \& Capela, R. (1988). An annotated checklist of the mosquitoes of continental Portugal (Diptera, Culicidae). Actas do III Congresso Ibérico de Entomologia, $233-253$.

Ribeiro, J., \& Ramos, H. (1999). Identification keys of the mosquitoes (Diptera: Culicidae) of continental Portugal, Açores and Madeira. European Mosquito Bulletin, 3, 1-11.

Rogers, D. J. (2006). Models for vectors and vector-borne diseases. Advances in Parasitology, 62, 1-35.

Rogers, D. J., Hay, S. I., \& Packer, M. J. (1996). Predicting the distribution of tsetse-flies in West-Africa using temporal Fourier processed meteorological satellite data. Annals of Tropical Medicine and Parasitology, 90, 225-241.

Rogers, D. J., Randolph, S. E., Snow, R. W., \& Hay, S. I. (2002). Satellite imagery in the study and forecast of malaria. Nature, 415, 710-715.

Romi, R., Boccolini, D., Vallorani, R., Severini, F., Toma, L., Cocchi, M., et al. (2012). Assessment of the risk of malaria re-introduction in the Maremma plain (Central Italy) using a multi-factorial approach. Malaria Journal, 11, 98.

Sainz-Elipe, S., Latorre, J. M., Escosa, R., Maisà, M., Fuentes, M. V., Mas-Coma, S., et al. (2010). Malaria resurgence risk in southern Europe: Climate assessment in an historically endemic area of rice fields at the Mediterranean shore of Spain. Malaria Journal, 9, 221. 
Sandholt, I., Rasmussen, K., \& Andersen, J. (2002). A simple interpretation of the surface temperature/vegetation index space for assessment of surface moisture status. Remote Sensing of Environment, 79(2-3), 213-224.

Service, M. W., \& Townson, H. (2002). The Anopheles vector. In D. A. Warrell, \& H. M. Gilles (Eds.), Essential malariology (pp. 59-84). London: Arnold.

Shililu, J., Ghebremeskel, T., Seulu, F., Mengistu, S., Fekadu, H., Zerom, M., et al. (2003). Larval habitat diversity and ecology of Anopheline larvae in Eritrea. Journal of Medical Entomology, 40(6), 921-929.

Shroeder, W., \& Schmidt, G. (2008). Mapping the potential temperature-dependent tertian malaria transmission within the ecoregions of Lower Saxony (Germany). International Journal of Medical Microbiology, 298, 38-49.

Sinka, M. E., Bangs, M. J., Manguin, S., Coetzee, M., Mbogo, C. M., Hemingway, J., et al. (2010). The dominant Anopheles vectors of human malaria in Africa, Europe and the Middle East: Occurrence data, distribution maps and bionomic précis. Parasites and Vectors, 3, 117

Soti, V., Tran, A., Bailly, J. S., Puech, C., Lo Seen, D., \& Begue, A. (2009). Assessing optical earth observation systems for mapping and monitoring temporary ponds in arid areas. International Journal of Applied Earth Observation and Geoinformation, 11(5), 344-351.

Sousa, C. A. (2008). Malaria vectorial capacity and competence of Anopheles atroparvus Van Thiel, 1927 (Diptera: Culicidae): Implications for the potential re-emergence of malaria in Portugal. (PhD Thesis). Universidade Nova de Lisboa, Instituto de Higiene e Medicina Tropical (187 pp.).

Steel, R. G., \& Torrie, J. H. (1960). Principles and procedures of statistics. New York: McGraw-Hill.
Stoops, C. A., Gionar, Y. R., Shinta, Sismadi P., Rachmat, A., Elyazar, I. F., \& Sukowati, S. (2008). Remotely-sensed land use patterns and the presence of Anopheles larvae (Diptera: Culicidae) in Sukabumi, West Java, Indonesia. Journal of Vector Ecology 33(1), 30-39.

Takken, W., Geene, R., Adam, W., Jetten, T. H., \& van der Velden, J. A. (2002). Distribution and dynamics of larval populations of Anopheles messeae and A. atroparvus in the delta of the rivers Rhine and Meuse, The Netherlands. Ambio, 31(3), 212-218.

Tran, A., Ponçon, N., Toty, C., Linard, C., Guis, H., Ferré, J. B., et al. (2008). Using remote sensing to map larval and adult populations of Anopheles hyrcanus (Diptera: Culicidae) a potential malaria vector in Southern France. International Journal of Health Geographics, 7, 9.

Vakali, A., Patsoula, E., Spanakos, G., Danis, K., Vassalou, E., Tegos, N., et al. (2012). Malaria in Greece, 1975 to 2010. Euro Surveillance, 17(47).

Warrell, D. A., \& Gilles, H. M. (2002). Essential Malariology (4th ed.). London, UK: Arnold. WHO (1978). The malaria situation in 1976. WHO Chronicle, 32, 9-17.

WHO (1982). World Health Organization: Manual on environmental management for mosquito control with special emphasis on malaria vectors. Geneva: WHO Offset Publication №66.

WHO (2010). World Malaria Report 2010. Geneva, Switzerland: World Health Organization. Zhou, G., Minakawa, N., Githeko, A. K., \& Yan, G. (2004). Association between climate variability and malaria epidemics in the East Africa highlands. Proceedings of the National Academy of Sciences of the United States of America, 101(8), 2375-2380. 